\title{
Traumatismos de la columna cervical alta: Clasificación tipológica, indicaciones terapéuticas y abordajes quirúrgicos (a propósito de 286 casos)
}

\author{
S. Martín-Ferrer
}

Servicio de Neurocirugía. Hospital Universitario Josep Trueta. Girona.

\section{Resumen}

Sobre la columna cervical alta $(\mathrm{C} 0-\mathrm{C} 1-\mathrm{C} 2)$ recae más del $60 \%$ de todas las lesiones traumáticas de la columna cervical; así, un $4-15 \%$ de todas las fracturas cervicales afectan al atlas y un $\mathbf{1 5 - 2 5 \%}$ al axis. Hoy en día las técnicas de neuroimagen permiten ver las lesiones anatómicas y funcionales producidas en el accidente, comprender los mecanismos patomecánicos de estas lesiones, establecer una correlación clínico-radiológica y funcional de la patología producida, clasificar todas las lesiones, predecir su posible comportamiento y evolución y establecer pautas terapéuticas adecuadas.

La clasificación de las lesiones traumáticas de C0-C1-C2 es imprescindible para tipificar la lesión y así definir los distintos tipos posibles de lesiones traumáticas producidas. En el contexto individual de cada paciente, cada tipo de lesión nos permite elegir el proceso terapéutico, médico o quirúrgico, más adecuado. De ello resulta una clara indicación terapéutica correcta para cada caso concreto.

En los casos con indicación quirúrgica, la finalidad de la intervención será: a) liberar elementos radiculomedulares atrapados mediante discectomías, corpectomías, laminectomías, evacuación de colecciones o ampliación de espacios; b) alinear segmentos vertebrales mediante tracción con compás, o con halo, manipulación o cirugía; c) estabilizar elementos vertebrales con técnicas quirúrgicas vía anterior, posterior o con dobles abordajes $360^{\circ}$ surgery; d) detener la evolución clínico-radiológica y, e) permitir la máxima recuperación funcional.

A pesar de que en los últimos años todas las posibles lesiones traumáticas del segmento occipitoatloaxoideo están correctamente clasificadas y tipificadas, las pautas de tratamiento no son uniformes ni todavía aceptadas o aplicadas de forma unánime.

En este trabajo se presenta la experiencia del autor en el manejo de este tipo de lesiones traumáticas. Se

Recibido; 12-09-05. Aceptado: 15-01-06 analizan 286 lesiones del segmento C0-C1-C2 y se correlaciona su clasificación y tipología con las pautas de tratamiento establecidas. Poner orden en la selección de casos para una indicación terapéutica concreta, correcta y eficaz de la instrumentación cervical junto a una ejecución terapéutica meticulosa y precisa, es un reto actual de los cirujanos que tratamos a estos pacientes.

PALABRAS CLAVE: Traumatismos columna cervical. Complejo occipitoatloaxoideo. Fijación transarticular C1C2. Fijación interarticular C1-C2. Atornillado anterior odontoides.

High cervical spine injuries: classification, therapeutic indications, and surgical approaches: 286 consecutive cases

\section{Summary}

Around $60 \%$ of all cervical fractures occur in the high cervical segment (C0-C1-C2); 4-15\% occurs in $\mathrm{C} 1$, and between $15-25 \%$ in the axis.

Nowadays, with high resolution imaging, we can see both anatomic and functional aspects of the fractures, as well as understand the mechanisms of injury. This can also allow us to study the evolution of the soft tissue lesions and fractures.

The classification of traumatic injuries in $\mathrm{CO}-\mathrm{C} 1-\mathrm{C} 2$ is basic in order to understand the mechanism of injury and natural history of these lesions. This also allow us to choose the correct or most adequate form of treatment.

In the cases where surgery is indicated we must: a) release of the cord or nerves, using standard techniques such as laminectomy, discectomy or corpectomy; b) align vertebral segments using traction, halo vest or surgery; c) estabilize the vertebral segments, using anterior, posterior or $360^{\circ}$ surgical approaches; d) stop the natural history of disease and e) allow maximal

Abreviaturas. AO: apófisis odontoides. FCO: fractura del cóndilo occipital. LRAA: luxación rotatoria atloaxoidea 


\section{functional recovery.}

Although there are good classifications that typify the fractures in the $\mathrm{C} 0-\mathrm{C} 1-\mathrm{C} 2$ segments, there are not clear or standard treatments for them.

This paper shows the personal experience of the author in the management of this type of fractures. The 286 patients with lesions in the high cervical segment $\mathrm{C} 0-\mathrm{C} 1-\mathrm{C} 2$ have been treated according to the classifications and recommendations already established in the literature. Selection of this cases and appropiate surgical approach is still a challenge for surgeons who deal with this problems.

KEY WORDS: Cervical injury. Occipitoatloaxial complex. Transarticular fixation C1-C2. Interarticular fixation C1C2. Transodontoid screws.

\section{Introducción}

La columna cervical alta está formada por las dos primeras vértebras cervicales, el atlas y el axis, incluyéndose a efectos biomecánicos y traumatológicos a los cóndilos occipitales y foramen magnum. A estas estructuras óseas deben añadirse todos los elementos ligamentosos, capsulares y musculares existentes, sin poder olvidar nunca las vitales estructuras vasculonerviosas contenidas en este complejo: médula espinal y arterias vertebrales.

El complejo C0-C1-C2 es un prodigio de la ingeniería humana. La primera vértebra cervical posee la mayor movilidad de toda la columna vertebral, y las articulaciones entre el hueso occipital y el atlas ( $\mathrm{C} 0-\mathrm{C} 1)$ y entre el atlas y el axis (C1-C2), anatómicamente muy especializadas, están biomecánicamente estructuradas de tal forma que, además de ser el nexo de unión osteoligamentoso entre la cabeza y el tronco, sobre ellas reside el poder de afirmación y negación, y numerosas expresiones mímicas del sentir humano. Sin embargo, su especial configuración anatómica y este mayor rango de movimientos las hace más vulnerables con mayor probabilidad de daño frente a numerosos procesos patológicos.

Sobre la columna cervical alta recae más del $60 \%$ de todas las lesiones traumáticas de la columna cervical. Si bien estas lesiones pueden resultar mortales en el mismo momento de producirse, la mayoría no producen inicialmente lesiones neurológicas o al menos éstas no son de gran intensidad. Algunos traumatismos pueden provocar o facilitar la aparición de lesiones neurológicas tardías, meses o incluso años después del accidente. Esta relativa bondad neurológica, en parte, es debida a que la relación continente/contenido en el complejo C0-C1-C2 favorece la protección medular, ya que sólo un tercio del canal vertebral está ocupado por la médula, otro tercio por estructuras capsuloligamentosas y el último tercio por LCR (regla de los tercios de Steel). Asimismo, las arterias vertebrales en este nivel poseen una marcada elasticidad que permite desplazamientos traumáticos de estructuras óseas sin apenas repercusión vascular patológica.

En los últimos 10 años he tenido la ocasión de atender a 286 pacientes con importantes lesiones traumáticas del complejo occipitoatloaxoideo (se excluyen aquellas lesiones no tipificadas y que se encuadran como "otras", p.e.: fracturas marginales de axis, de láminas o apófisis espinosas de axis, de apófisis transversas de atlas o axis y cuyo tratamiento es siempre ortopédico). De estos 286 casos, 152 han precisado tratamiento quirúrgico y los restantes 134 han sido tratados mediante métodos ortopédicos, la mayoría con ortesis moldeadas, cervicales o occipitocervicales (Tabla 1).

\section{Clasificación}

El desarrollo y la aparición de sucesivas técnicas de neuroimagen han permitido visualizar correctamente todas las lesiones traumáticas osteoligamentosas del complejo C0-C1-C2, comprender los mecanismos traumáticos patomecánicos de producción de las lesiones, su posible comportamiento evolutivo y así clasificar anatómicamente las muy diversas lesiones de este complejo; ello permite predecir su posible peligrosidad y comportamiento evolutivo radiológico y clínico. (Tabla 2)

Paralelamente se han desarrollado diversos y eficaces procedimientos terapéuticos, que permiten tratar a la gran mayoría de estas lesiones y neutralizar esta potencial peligrosidad. (Tabla 3)

Los traumatismos sobre el complejo $\mathrm{C} 0-\mathrm{C} 1-\mathrm{C} 2$ pueden provocar lesiones musculares, ligamentosas, articulares $\mathrm{u}$ óseas; en muchos casos existen lesiones mixtas con posibilidad o potencialidad de afectación medulovascular, configurando los diversos tipos de luxaciones o fracturas de este complejo. La gran mayoría de estas lesiones poseen un tremendo potencial evolutivo peyorativo.

\section{Luxación occipitoatloidea}

Se produce por la ruptura total de los ligamentos y cápsulas articulares que unen el atlas y la odontoides al hueso occipital con la consiguiente dislocación de éstos, en accidentes a alta velocidad. Esta lesión es más frecuente en niños, ya que la diferente relación entre la cabeza y el cuerpo en la infancia potencia la inercia traumática necesaria para producir este tipo de lesiones.

La separación traumática entre el atlas y el hueso occipital en la mayoría de los casos es incompatible con la vida, ya que puede ocasionar la sección de la médula o de las arterias vertebrales. En la literatura se han descrito menos de 100 casos documentados que han logrado sobre- 
Tabla 1

Casuística 1993 - 2004

\begin{tabular}{|c|c|c|c|}
\hline $\begin{array}{l}\text { Tipo fractura } \\
N^{o} \text { casos: } 286\end{array}$ & $\begin{array}{l}\text { Tratamiento médico } \\
N^{o}: 134\end{array}$ & $\begin{array}{l}\text { Tratamiento quirúrgico } \\
N^{o}: 152\end{array}$ & Tipo tratamiento quirúrgico \\
\hline $\begin{array}{l}\text { Fracturas agudas de la apófisis } \\
\text { odontoides: } \\
\text {-Apex } \\
\text {-Base }\end{array}$ & $\begin{array}{l}1 \\
4\end{array}$ & 74 & Atornillado anterior de axis ( 74 casos) \\
\hline $\begin{array}{l}\text { Fracturas pedículos del axis } \\
\text {-Tipo I } \\
\text {-Tipo II } \\
\text {-Tipo IIa } \\
\text {-Tipo III }\end{array}$ & $\begin{array}{r}16 \\
6 \\
- \\
-\end{array}$ & $\begin{array}{r}- \\
9 \\
10 \\
-\end{array}$ & $\begin{array}{l}* \mathrm{ACIF} \text { C2-C3 }(5 \text { casos }) \\
\text { Fijación posterior C2-C3 }\end{array}$ \\
\hline $\begin{array}{l}\text { Fracturas del cuerpo del axis } \\
\text {-Tipo I (coronal) } \\
\text {-Tipo II (sagital) } \\
\text {-Tipo III (axial) }\end{array}$ & $\begin{array}{r}10 \\
4 \\
16\end{array}$ & $\begin{array}{r}- \\
1 \\
11\end{array}$ & $\begin{array}{l}\text { Fijación C1-C2 posterior (5) } \\
\text { Fijación occipitocervical (6) } \\
\text { Fijación C2 anterior (1) }\end{array}$ \\
\hline $\begin{array}{l}\text { Luxación C0-C1 } \\
\text {-Tipo I } \\
\text {-Tipo II } \\
\text { Tipo III }\end{array}$ & $\begin{array}{l}1 \\
- \\
-\end{array}$ & $\begin{array}{l}- \\
- \\
-\end{array}$ & \\
\hline $\begin{array}{l}\text { Fracturas cóndilo occipital } \\
\text {-Tipo I } \\
\text {-Tipo II } \\
\text {-Tipo III }\end{array}$ & $\begin{array}{l}3 \\
2 \\
-\end{array}$ & $\begin{array}{l}- \\
- \\
-\end{array}$ & \\
\hline $\begin{array}{l}\text { Luxación rotatoria atloaxoidea } \\
\text {-Tipo I } \\
\text {-Tipo II } \\
\text {-Tipo III } \\
\text {-Tipo IV }\end{array}$ & $\begin{array}{l}5 \\
2 \\
- \\
-\end{array}$ & $\begin{array}{l}- \\
2 \\
- \\
-\end{array}$ & Fijación C1-C2 posterior (2) \\
\hline $\begin{array}{l}\text { Ruptura ligamento transverso } \\
\text {-Tipo I } \\
\text {-Tipo II }\end{array}$ & - & $\begin{array}{l}3 \\
2\end{array}$ & $\begin{array}{l}\text { Artrodesis C1-C2 posterior (4) } \\
\text { Fijación C1-C2 posterior (1) }\end{array}$ \\
\hline $\begin{array}{l}\text { Fracturas del atlas } \\
\text {-Tipo a } \\
\text {-Tipo b } \\
\text {-Tipo c } \\
\text {-Tipo d } \\
\text {-Tipo e } \\
\text {-Tipo f } \\
\text {-Tipo g }\end{array}$ & $\begin{array}{r}8 \\
38 \\
6 \\
- \\
- \\
4 \\
3\end{array}$ & $\begin{array}{l}- \\
- \\
- \\
2 \\
2 \\
- \\
5\end{array}$ & $\begin{array}{l}\text { Fijación occipitocervical (4) } \\
\text { Tipo g = Ruptura lig. Transverso) }\end{array}$ \\
\hline $\begin{array}{l}\text { Fracturas crónicas de la base } \\
\text { de la apófisis odontoides }\end{array}$ & 2 & 28 & $\begin{array}{l}\text { Fijación occipitocervical (12) } \\
\text { Fijación } 360^{\circ}(8) \\
\text { Fijación C1-C2 posterior (5) } \\
\text { Artrodesis C1-C2 posterior (3) }\end{array}$ \\
\hline Fracturas crónicas pedículos del axis & - & 3 & Fijación occipitocervical (3) \\
\hline Fracturas asociadas & & & Tratamiento según análisis de cada fractura \\
\hline
\end{tabular}

Artrodesis C1-C2 posterior $=$ Atornillado transarticular según técnica de Magerl

Fijación C1-C2 posterior $=$ Fusión interarticular según técnica de Goel-Harms

Fijación $360^{\circ}=$ Magerl o Goel + fijación interlaminar C1-C2

Fijación occipitocervical: siempre artrodesis $\mathrm{C} 1-\mathrm{C} 2$ posterior incluida en el montaje

*ACIF $=$ Artrodesis cervical anterior mediante caja y placa C2-C3 


\section{Tabla 2}

Clasificación de las lesiones traumáticas occipitoatloaxoideas

\begin{tabular}{|c|c|}
\hline $\begin{array}{l}\text { Luxación occipitoatloidea } \\
\text { Traynelis, } 1986\end{array}$ & $\begin{array}{l}\text { Tipo I, desplazamiento anterior de las masas del atlas } \\
\text { Tipo II, desplazamiento longitudinal occipitoatloideo } \\
\text { Tipo III, desplazamiento posterior de las masas del atlas }\end{array}$ \\
\hline $\begin{array}{l}\text { Fracturas del cóndilo occipital } \\
\text { Anderson y Montesano, } 1988\end{array}$ & $\begin{array}{l}\text { Tipo I, fractura aislada del cóndilo occipital } \\
\text { Tipo II, fractura del cóndilo con extensión al clivus o hueso occipital } \\
\text { Tipo III, avulsión del cóndilo }\end{array}$ \\
\hline $\begin{array}{l}\text { Luxación rotatoria atloaxoidea } \\
\text { Fielding y Hawkins, } 1977\end{array}$ & $\begin{array}{l}\text { Tipo I, rotación anterior de una masa del atlas } \\
\text { Tipo II, rotación o luxación anterior de una masa del atlas. IAD* }>3 \mathrm{~mm} \text {. } \\
\text { Tipo III, luxación anterior de ambas masas del atlas. IAD }>5 \mathrm{~mm} \text {. } \\
\text { Tipo IV, luxación posterior de una o dos masas del atlas }\end{array}$ \\
\hline $\begin{array}{l}\text { Ruptura aislada del ligamento } \\
\text { transverso del atlas } \\
\text { Dickman, } 1996\end{array}$ & $\begin{array}{l}\text { Tipo I, ruptura medial del ligamento transverso del atlas } \\
\text { Tipo II, desinserción o fractura del tubérculo de inserción al atlas del } \\
\text { ligamento transverso }\end{array}$ \\
\hline $\begin{array}{l}\text { Fracturas del atlas } \\
\text { Jefferson, } 1920\end{array}$ & $\begin{array}{l}\text { Tipo a, fractura del arco anterior uni o bilateral } \\
\text { Tipo b, fractura del arco posterior uni o bilateral } \\
\text { Tipo c, fractura simple de una masa lateral del atlas } \\
\text { Tipo d, fractura conminuta de una masa lateral del atlas } \\
\text { Tipo e, fractura bilateral de los arcos anterior y posterior } \\
\text { Tipo f, fracturas lineales o cruzadas del arco anterior y posterior } \\
\text { Tipo g, ruptura aislada del ligamento transverso del atlas }\end{array}$ \\
\hline $\begin{array}{l}\text { Fracturas de la odontoides } \\
\text { Martín-Ferrer, } 1997\end{array}$ & $\begin{array}{l}\text { Fractura del ápex } \\
\text { Fractura de la base }\end{array}$ \\
\hline $\begin{array}{l}\text { Fracturas de los pedículos del axis } \\
\text { Levine-Effendi y Edwards, } 1985\end{array}$ & $\begin{array}{l}\text { Tipo I, }<\text { de } 3 \mathrm{~mm} \text {. de desplazamiento y sin angulación C2-C3 } \\
\text { Tipo II, > de } 3 \mathrm{~mm} \text {. de separación y angulación C2-C3 }<\text { a } 11^{\circ} \\
\text { Tipo IIa, > de } 3 \mathrm{~mm} \text {. de separación y angulación C2-C3 > a } 11^{\mathrm{o}} \\
\text { Tipo III, luxación total C2-C3 (hangman's fracture) }\end{array}$ \\
\hline $\begin{array}{l}\text { Fracturas del cuerpo del axis } \\
\text { Benzel, } 1994\end{array}$ & $\begin{array}{l}\text { Tipo I, fractura coronal } \\
\text { Tipo II, fractura sagital } \\
\text { Tipo III, fractura transversa }\end{array}$ \\
\hline Fracturas crónicas & (múltiples posibilidades) \\
\hline Fracturas asociadas & (multiples combinaciones) \\
\hline Otras & $\begin{array}{l}\text { Fracturas marginales del cuerpo del axis, de las láminas, facetas o apófisis } \\
\text { espinosa de axis, de apófisis transversas de atlas o axis }\end{array}$ \\
\hline
\end{tabular}

*IAD, intervalo atlodental

vivir a esta lesión. En la mayoría de casos su diagnóstico está inmerso en implicaciones médico-legales dirigidas por médicos forenses.

Los actuales y modernos sistemas de emergencias médicas, con estabilización, tratamiento, recogida y transporte medicalizado de estos graves lesionados, desde el mismo lugar del accidente hasta el hospital, puede permitir un mayor número de diagnósticos en vivos.

La luxación occipitoatloidea fue clasificada por Traynelis $^{85}$ en 1986 en Tipo I con desplazamiento anterior de las masas del atlas; Tipo II con desplazamiento longitudinal entre el atlas y el hueso occipital y Tipo III con desplaza- 


\section{Tabla 3}

Técnicas quirúrgicas y experiencia personal en patología traumática C0-C1-C2

\begin{tabular}{|c|c|}
\hline - Artrodesis transarticular posterior C1-C0 (Grob ${ }^{42}, 2001$ - González $\left.{ }^{41}, 2003\right)$ & - \\
\hline - Atornillado anterior de la odontoides (Nakanishi ${ }^{74}, 1980$ - Böhler $\left.{ }^{16}, 1982\right)$ & 74 casos \\
\hline - Fijación interlaminar C1-C2 (Gallie $\left.{ }^{34}, 1920\right)$ & 17 casos \\
\hline - Fijación atlantoaxial transoral $\left(\mathrm{Harms}^{61}, 2001\right)$ & - \\
\hline - Artrodesis transarticular anterior C1-C2 (Lesoin $\left.{ }^{63}, 1987\right)$ & - \\
\hline - Artrodesis transarticular posterior C1-C2 (Barbour ${ }^{9}, 1971$ - Magerl $\left.{ }^{65}, 1979\right)$ & 7 casos \\
\hline - Fijación posterior C1-C2 360(Sonntag, 1980) & 8 casos \\
\hline - Fijación interarticular posterior C1-C2 (Goel ${ }^{39}, 1994$ - Harms $\left.{ }^{49}, 2001\right)$ & 13 casos \\
\hline - Fijación occipitocervical & 25 casos \\
\hline - Fijación interfacetaria C2-C3 (Roy-Camille, 1977 - Magerl, 1977) & 14 casos \\
\hline - Artrodesis cervical anterior C2-C3 (Orozco\&Llovet, 1972) & 5 casos \\
\hline \multicolumn{2}{|l|}{ - Técnicas endoscópicas } \\
\hline - Técnicas mixtas & \\
\hline
\end{tabular}

miento posterior. La dislocación longitudinal, con verdadera separación de la cabeza de la columna vertebral, es la más frecuente, seguida de la dislocación anterior y sólo en un número muy pequeño de casos se objetiva un desplazamiento posterior del complejo atloaxoideo. Estas lesiones pueden asociarse a fracturas de la punta de la odontoides.

Cuando existe sospecha clínica, el diagnóstico puede confirmarse con estudios de neuroimagen, sobre todo en aquellos casos con dislocación permanente. Sin embargo, algunos pacientes que han sufrido una grave luxación atlooccipital pueden llegar al hospital con sus estructuras óseas repuestas, aunque totalmente inestables, lo que dificultará enormemente su diagnóstico y la potencialidad de agravamiento o aparición de sintomatología neurológica. $\mathrm{Si}$ a esto añadimos que pueden asociarse graves traumatismos craneoencefálicos o sistémicos, el diagnóstico puede pasar desapercibido.

Para su diagnóstico, los estudios de neuroimagen deben ser dirigidos en la búsqueda de signos indirectos, como el aumento (hinchazón) de las partes blandas prevertebrales altas, aumento de la distancia entre el basion y la punta de la odontoides o separación articular entre los cóndilos occipitales y la superficie articular craneal de las masas de C1.

Ante la sospecha clínica o patomecánica de la existencia de una luxación atlooccipital, debe obtenerse una RX craneocervical muy bien centrada en proyección lateral y a ser posible en proyección anteroposterior transoral.
Para confirmar su diagnóstico mediante radiología simple, diversos autores han propuesto diversas medidas sobre la placa radiológica cervical simple lateral. De los diversos métodos referidos en la literatura por Powers ${ }^{79}$, Dublin ${ }^{26}$, Lee $^{62}$, Wackensheim ${ }^{87}$ o Wholey ${ }^{89}$, actualmente se acepta como más seguro el método de medida descrito por Harris ${ }^{50}$ en 1994; según este autor se confirma el diagnóstico de luxación atlooccipital cuando exista una distancia superior a $+12 \mathrm{~mm}$. ó $-4 \mathrm{~mm}$., entre el centro del borde inferior del basion y la línea trazada perpendicularmente a través del borde posterior del cuerpo del axis y/o la existencia de un desplazamiento superior a $12 \mathrm{~mm}$. entre el borde inferior del basion y la apófisis odontoides. En la placa radiológica anteroposterior transoral puede objetivarse una separación entre los cóndilos occipitales y las masas de $\mathrm{C} 1$. También podemos objetivar un aumento de las partes blandas prevertebrales en las placas radiológicas laterales craneocervicales. La TAC o la RNM craneocervical pueden ayudar al diagnóstico, al detectar desalineaciones craneocervicales, signos de hemorragia subaracnoidea, hinchazón en partes blandas o signos de lesión medular.

La luxación atlooccipital es una lesión muy inestable que puede ocasionar distracción o compresión de la médula espinal, tronco cerebral o de pares craneales y alteraciones vasculares por estiramiento de las arterias vertebrales. Clínicamente puede manifestarse por paresias de los VI, X y XII pares craneales, monoparesias, hemiparesias o tetraparesias, o disfunción respiratoria. También puede 
provocar una tetraplejia completa con apnea. Un 20\% de los pacientes pueden llegar al hospital con una exploración neurológica normal. Los servicios de emergencia o la exploración en la sala de urgencias nos orientarán sobre la existencia de esta lesión si objetivan un hematoma palpable $\mathrm{y}$ visible en la faringe.

Son lesiones que prácticamente no tienen ninguna posibilidad de curación espontánea. Incluso aquellos casos que inicialmente están asintomáticos presentarán deterioro neurológico tardío, si no son diagnosticados y tratados, ya que las disrupciones y avulsiones capsuloligamentosas tienen escasas opciones de reparación espontánea. Los pacientes con lesiones neurológicas incompletas deben ser tratados de urgencia, por el riesgo inminente de progresión clínica. La cirugía mediante una fijación instrumentada occipitocervical o, en ocasiones, una fijación interarticular posterior atlooccipital ${ }^{41,42} \operatorname{logra}$ una correcta alineación y estabilización de la luxación y así impide la aparición o empeoramiento de la clínica neurológica.

Un $10 \%$ de los pacientes con luxación atlooccipital sometidos a tracción cervical presentan empeoramiento clínico neurológico. Según Dickman y Sonntag ${ }^{24}$ la inmovilización con ortesis tipo Philadelphia está contraindicada, ya que, como la tracción cervical reproduce el mecanismo del accidente puede ocasionar daño neurológico sobreañadido. Para estos autores, la inmovilización debe efectuarse con halo craneotorácico sólo en espera de una fijación quirúrgica que debe efectuarse lo antes posible.

Futuros estudios con TAC 3D, RNM de alta resolución que permitan valorar fehacientemente desplazamientos, reposiciones, lesiones parciales o totales capsuloligamentosas, en definitiva posibles lesiones no inestables, permitirán que se defina un subgrupo de pacientes tributarios de tratamiento ortopédico con halo craneal. En la actualidad hasta un $30 \%$ de los pacientes correctamente tratados logran la supervivencia con fijaciones estables y escasas secuelas neurológicas.

\section{Fracturas del cóndilo occipital}

Aunque la fractura del cóndilo occipital (FCO) fue descrita por Bell ${ }^{11}$ en 1817 , este tipo de lesión pocas veces es diagnosticada en nuestro medio. La generalización de los estudios TAC y TAC 3D permite en las dos últimas décadas un aumento de casos diagnosticados.

Desde 1966 a 2001 existen 218 trabajos publicados referentes a FCO, en los que se describen menos de 100 casos con este tipo de lesión.

Clínicamente deberemos sospechar su presencia en pacientes afectos de traumatismos craneales contra superficies romas a alta velocidad, dolor o contractura occipital, reducción de la movilidad craneocervical, paresias de pares bajos $^{86}$ (glosofaríngeo, hipogloso, vago, accesorio espinal o motor ocular común), hinchazón o hematoma de partes blandas retrofaríngeas, vértigo, nistagmus o tortícolis. Un tercio de los casos se asocian a otras fracturas cervicales.

La radiología simple no es útil para el diagnóstico de estas lesiones siendo la TAC craneal el mejor método de diagnóstico ${ }^{88}$.

En 1988, Anderson y Montesano 4 clasifican a estas fracturas en Tipo I, fractura aislada del cóndilo que se considera inestable si existe conminución del mismo; Tipo II o fractura del cóndilo con extensión al clivus o hueso occipital, siendo siempre estables y Tipo III con avulsión del cóndilo y consideradas inestables. El tipo más frecuente es el III, seguido del II y del I en la proporción 3/2/1.

El tratamiento en aquellos casos sin clínica neurológica y sin desplazamientos marcados es inicialmente conservador. Si se demuestra compresión sobre el tronco cerebral por fragmentos desplazados se procederá a cirugía liberadora con exéresis de los fragmentos y fusión occipitocervical.

La mayoría de casos pueden tratarse con ortesis Minerva occipitocervicales moldeadas. Si aparecen alteraciones neurológicas, nuevos estudios con TAC o RNM podrán hacernos replantear la necesidad de cirugía.

\section{Luxación rotatoria atloaxoidea}

Aunque la luxación rotatoria atloaxoidea (LRAA) puede presentarse en la edad adulta, su incidencia es casi exclusiva en la infancia ${ }^{28}$. Puede estar causada por traumatismos banales en ejercicios gimnásticos de rotación sagital del tronco, en el transcurso de infecciones de las vías respiratorias altas (enfermedad de Grisel), o en traumatismos graves, pero muchas veces aparece espontáneamente sin poder relacionarse con causa alguna.

La cabeza se encuentra rotada hacia un lado, estando ésta ladeada hacia el otro (posición de cock-robin en la literatura inglesa). El paciente no puede rotar la cabeza hacia el otro lado y se suele asociar con un espasmo intenso del músculo esternocleidomastoideo medial a la rotación. Cualquier intento voluntario o forzado de restablecer la posición normal de la cabeza provoca intenso dolor cervical y normalmente no se consigue. Casi nunca existe clínica neurológica por lo holgado del canal vertebral a este nivel (regla de los tercios).

El diagnóstico radiológico puede obtenerse mediante estudios de neuroimagen. En las RX simples puede objetivarse una desalineación compensatoria de las apófisis espinosas y una desalineación de las masas laterales de $\mathrm{C} 1$, una de las cuales se encuentra en posición anterior a la odontoides. Los estudios TAC y TAC 3D funcionales aportan datos suficientes que permiten valorar la situación y tipo de la LRAA. A este respecto Fielding y Hawkins ${ }^{31}$ en 1977 clasifican las LRAA en cuatro tipos. El Tipo I representa 


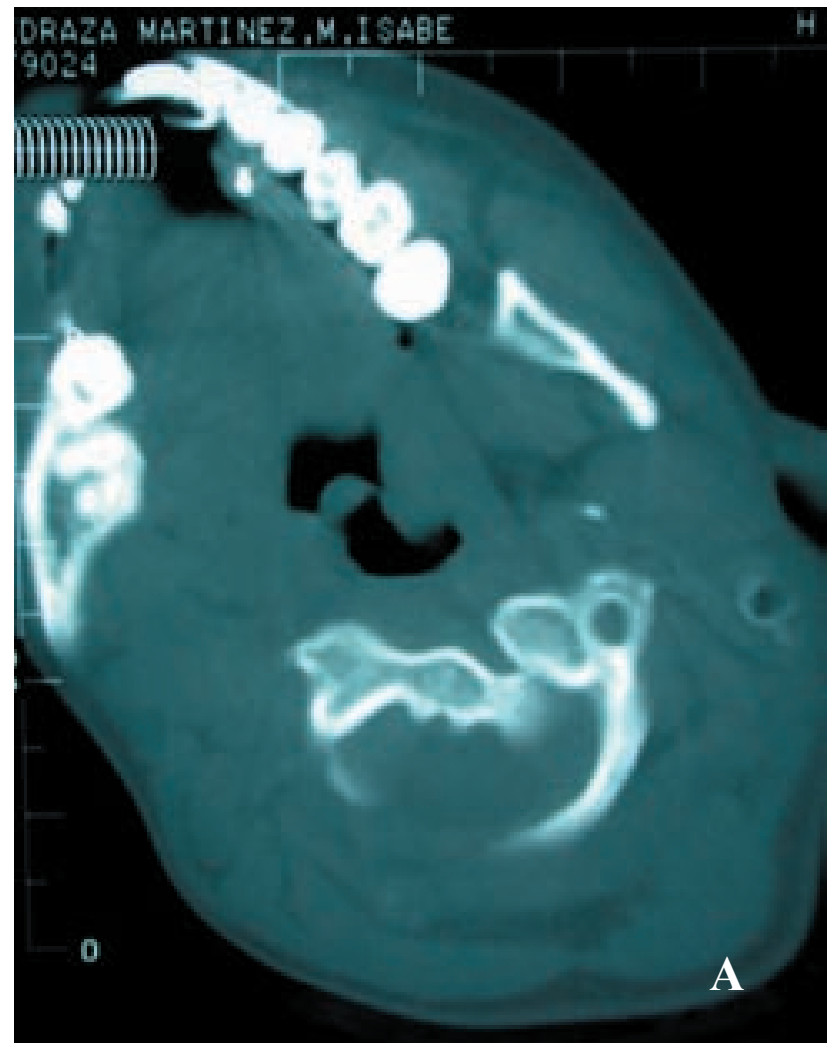

Figura 1. Luxación rotatoria atloaxoidea. (1A-B-C): Tipo I

una rotación anterior unilateral de una masa del atlas que pivota alrededor de la odontoides manteniéndose la integridad del ligamento transverso del atlas. El Tipo II, en el que también existe un desplazamiento unilateral anterior de una masa del atlas, éste se realiza pivotando sobre la articulación atloaxoidea contralateral lo que provoca una separación atloaxoidea de hasta $5 \mathrm{~mm}$. El ligamento transverso del atlas puede, en este caso, ser deficiente. El Tipo III ocurre cuando existe una subluxación anterior de ambas masas laterales del atlas. La separación atloaxoidea puede superar los 5 mm., lo que presupone un ligamento transverso totalmente incompetente. Los raros casos del Tipo IV representan una subluxación uni o bilateral posterior de las masas del atlas, se suelen presentar en coexistencia con una epifisiolisis o bien con una agenesia de la odontoides.

La mayoría de LRAA corresponden a los tipos I y II y por este orden. La gran mayoría de LRAA, de los tipos I y II, se reducen y retornan a la normalidad funcional en menos de una semana con medidas terapéuticas simples (ortesis blandas, analgésicos y relajantes musculares); únicamente las LRAA que persisten más allá de una semana necesitarían manipulaciones o tracciones para su reducción, seguido de la colocación de sistemas de contención como Minervas moldeadas ${ }^{35}$, o según algunos autores halos craneotorácicos entre 8 y 16 semanas $^{10,12}$.

Aquellos casos recidivantes, no reductibles por manipu-
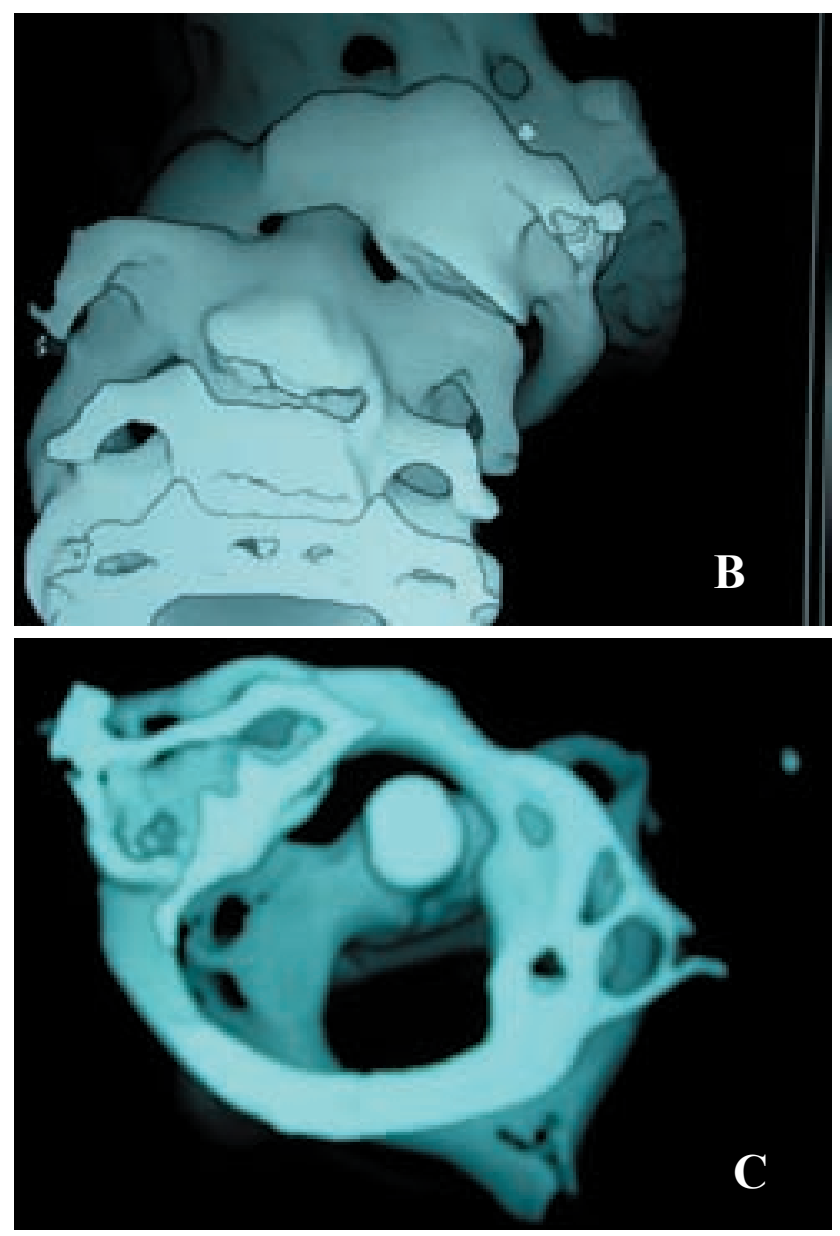

lación o tras tres semanas de tratamiento ortésico, podrán precisar de un tratamiento quirúrgico mediante fijaciones instrumentadas posteriores.

Los casos con luxaciones tipo III o IV precisaran tratamiento quirúrgico mediante fijaciones instrumentadas posteriores.

La experiencia quirúrgica de este autor se limita a dos casos con una luxación total unilateral tipo II crónica, con práctica ptosis anterior de una masa de $\mathrm{C} 1$ e irreductible tanto con medios conservadores mediante ortesis y tracción como en acto quirúrgico, que finalmente se trató con una fusión interlaminar $\mathrm{C} 1-\mathrm{C} 2{ }^{15}$. Cedió el dolor pero sólo se corrigió parcialmente la actitud en cock-robin de la cabeza. (Fig. 1)

\section{Ruptura aislada del ligamento transverso del atlas}

Con este tipo de traumatismo se produce una luxación atloaxoidea anterior con una separación entre el arco anterior del atlas y la apófisis odontoides superior a $3 \mathrm{~mm}$. en los adultos y a $5 \mathrm{~mm}$. en los niños. Clínicamente, en la mayoría de los casos, sólo se produce dolor cervical y muchas veces el diagnóstico es tardío, al constatar en radiografías funcio- 

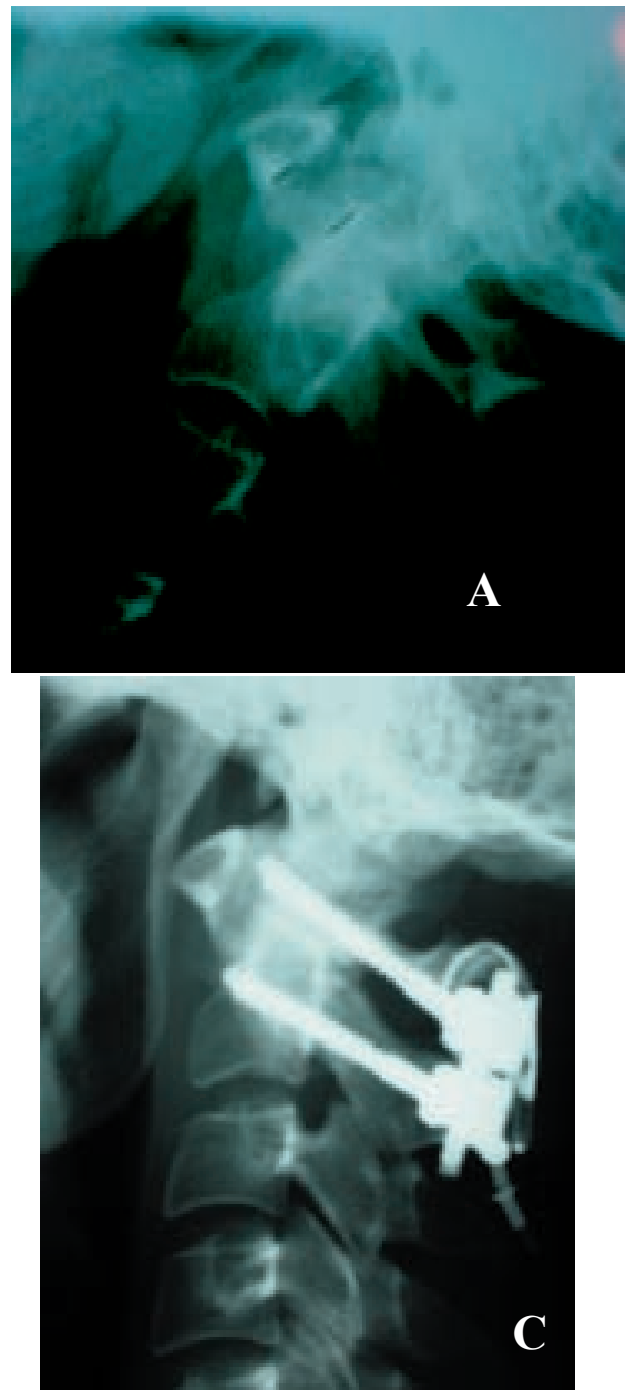

Figura 2. Ruptura aguda del ligamento transverso del atlas. (2A) y (2B) RX y RNM: Luxación atloaxoidea $>$ a 5 $\mathrm{mm}$. tras accidente de tráfico en una paciente de 38 años. (2C) y (2D): Artrodesis interarticular C1-C2 con tornillos y barras según técnica de Goel y fijación interlaminar C1C2 con malla de titanio, cable laminar y hueso autólogo.

nales, semanas o incluso meses después del traumatismo, un intervalo atlodental aumentado que confirma la luxación.

En 1996 Dickman $^{25}$ clasifica estas lesiones en dos tipos. El Tipo I, que representa una ruptura medial del ligamento con indemnidad de los elementos óseos y el Tipo II, en el que existe una desinserción o fractura del tubérculo óseo de inserción del ligamento a la masa lateral del atlas.

El diagnóstico radiológico puede objetivarse ante la presencia de una luxación atloaxoidea en las RX simples, fracturas con mayor o menor grado de conminución del tubérculo de inserción en los estudios TAC o la visualización directa de la ruptura o desinserción del ligamento transverso del atlas en la RNM.
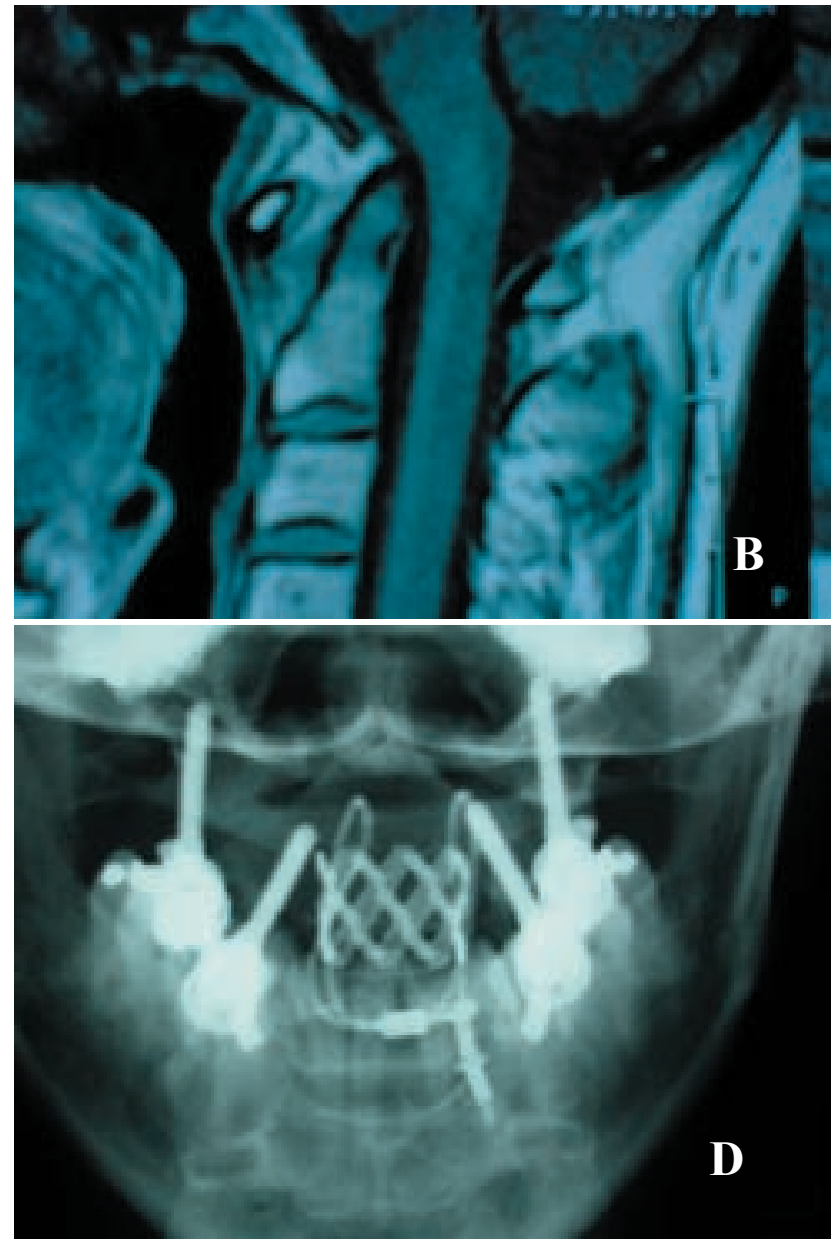

Puede asociarse a fracturas de la odontoides o del atlas $^{84}$.

El Tipo I es una lesión muy inestable por las escasas posibilidades de reparación ligamentosa espontánea. El Tipo II, y bajo inmovilización externa con Minervas cervicales, tiene la posibilidad de curar, si se consigue la consolidación de la fractura o de la avulsión del tubérculo de inserción del ligamento. Esta curación se produce con medios conservadores en un $74 \%$ de los casos.

Aquellos casos en que no se consigue una reparación de la fractura o bien en los que la lesión se considera inestable desde el principio o su diagnóstico se efectúa tardíamente, deberán ser tratados quirúrgicamente mediante una fijación posterior $\mathrm{C} 1-\mathrm{C} 2$ transarticular o interarticular asociada a una fijación interlaminar C1-C2. (Fijación posterior C1-C2 $360^{\circ}$ ) (Fig.2)

\section{Fracturas del atlas}

Representan del 4-15\% de todas las fracturas de la columna cervical y del 1-3\% de todas las fracturas de la columna vertebral. Un $39-56 \%$ se presentan como fracturas aisladas y en un 

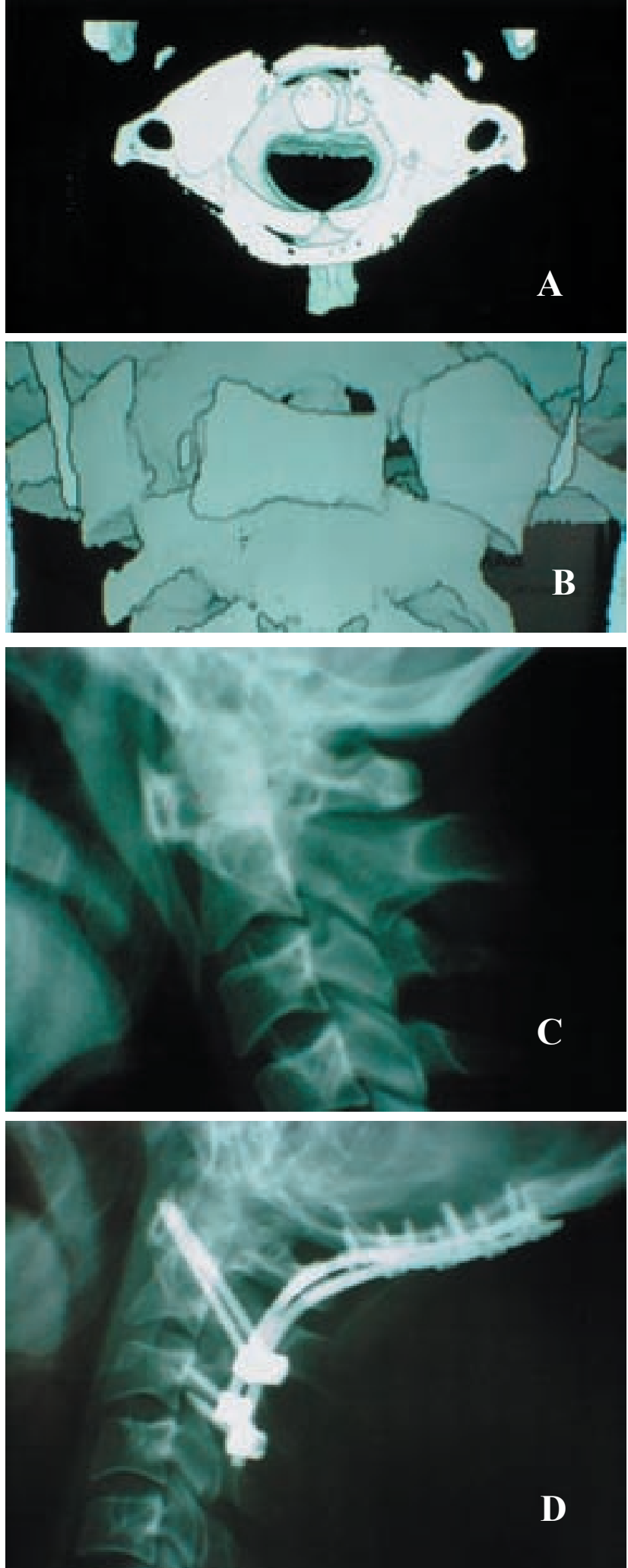

$50 \%$ de los casos se asocian a fracturas del axis.

Dada la especial configuración anatómica del atlas, los traumatismos sobre esta vértebra pueden producir una
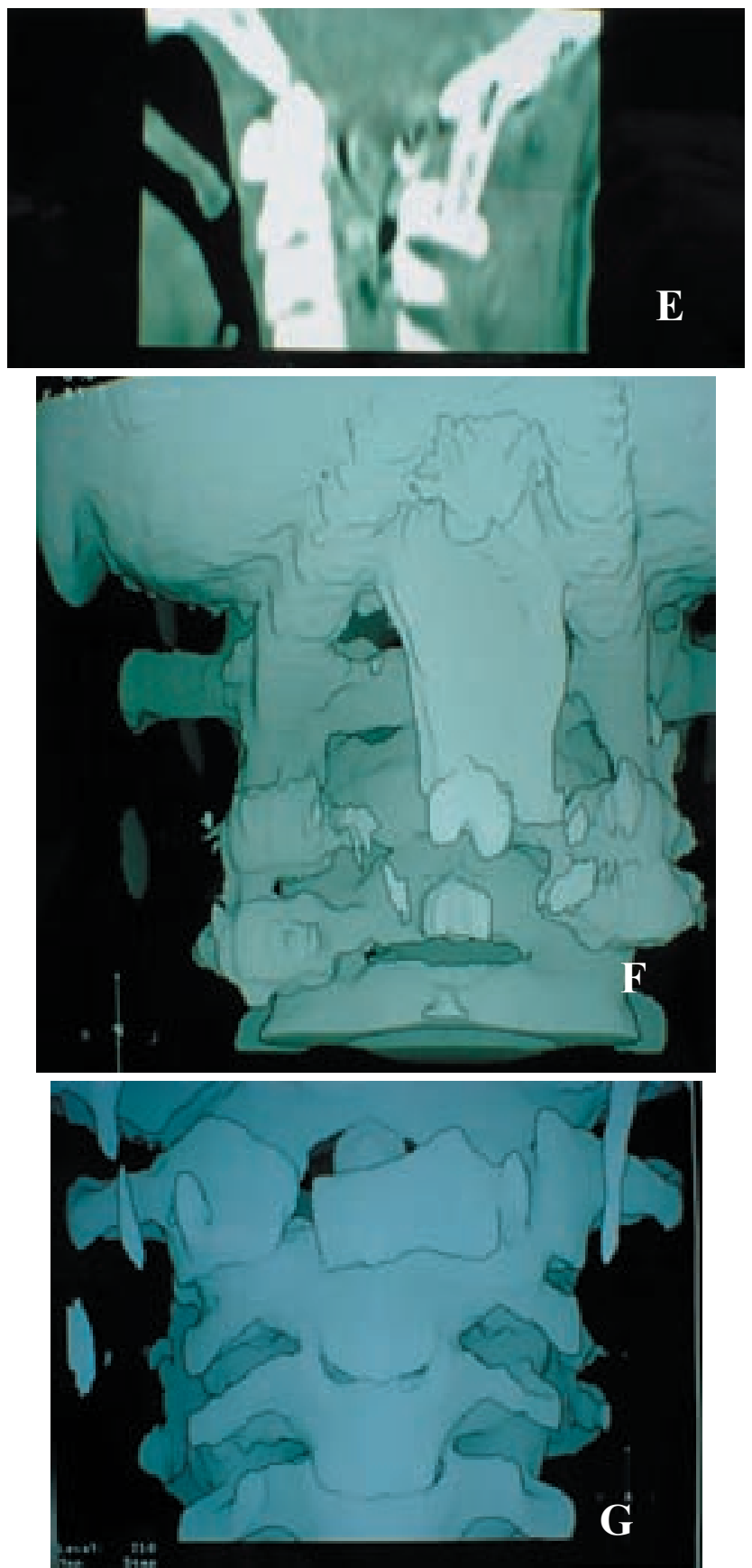

Figura 3. Fractura de atlas. (3A) TAC C1: fractura bilateral ambos arcos del atlas. (3B) TAC C1-C2: fractura de Jefferson tipo e, Spence + (separación masas de C1>6.9 $\mathrm{mm}$ ). (3C) RXC1-C2: inestabilidad atloaxoidea. (3D): fijación occipitocervical. (3E): TAC: reducción de la luxación. Nótese el injerto óseo entre occipital y espinosa de C2. (3F) y (3G): TAC $3 D$ nótese la fijación instrumentada con barras y tornillos y la artrodesis ósea

considerable combinación de lesiones sobre las masas o los arcos de esta vértebra, lesiones ya clasificadas por Jeffer- 

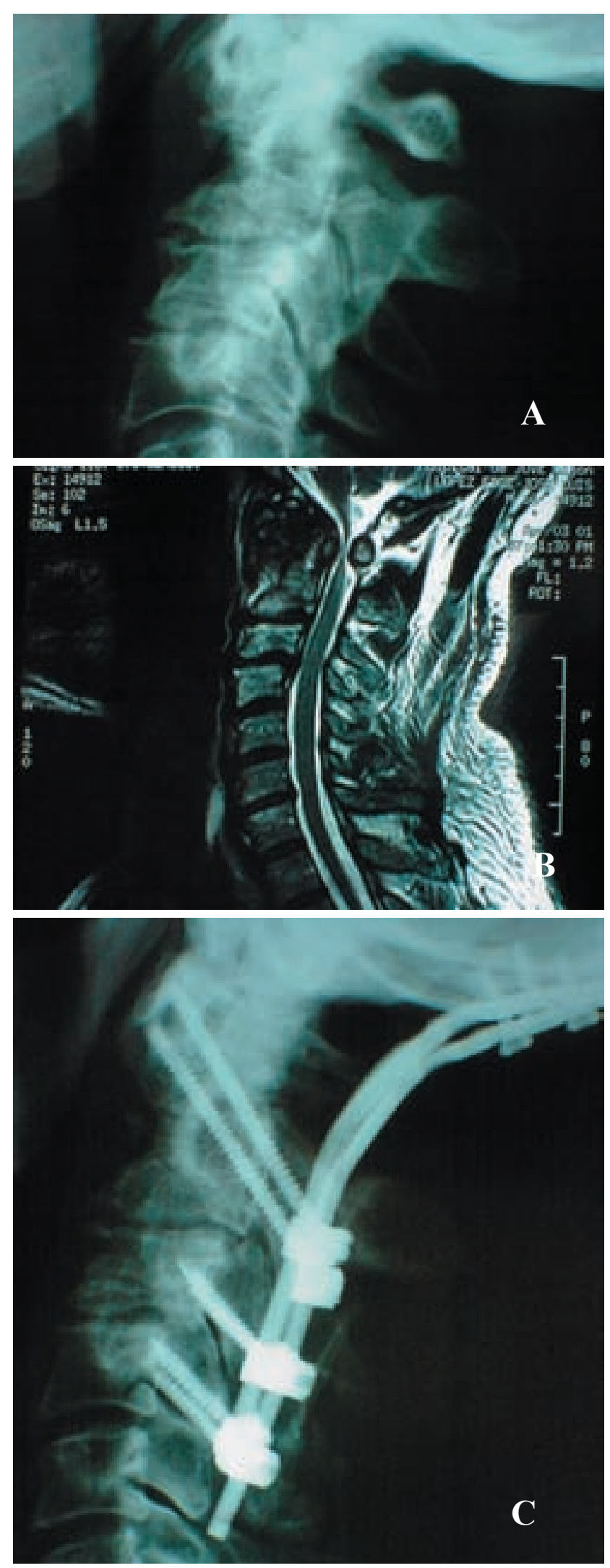

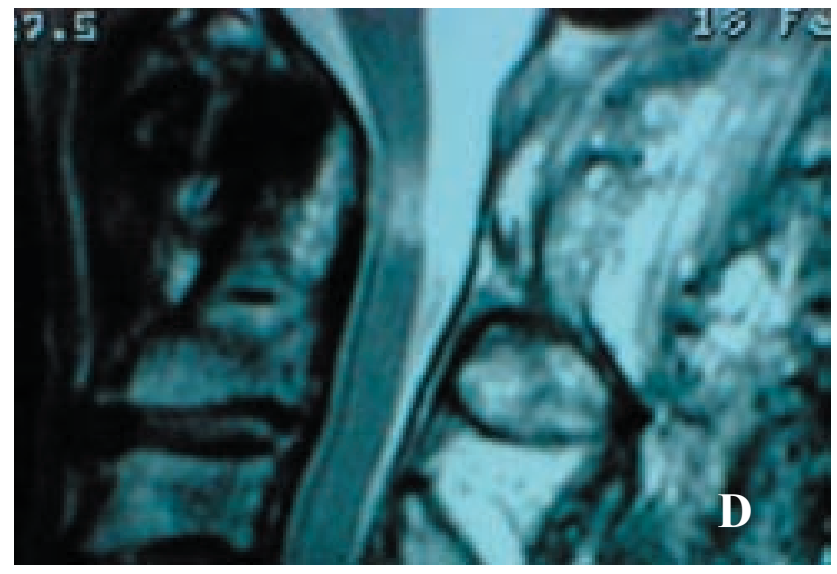

Figura 4. Ruptura crónica del ligamento transverso del atlas. Paciente de 63 años, accidente deportivo a la edad de 40 años. (4A) y (4B): RX y RNM con luxación atloaxoidea y compromiso medular severo. (4C) y (4D): $R X$ y RNM postquirúrgicas con fijación occipitocervical y liberación medular

$\operatorname{son}^{56}$ en 1920 en siete tipos: Tipo a que representa una fractura del arco anterior uni o bilateral. Tipo $b$ con fractura del arco posterior uni o bilateral. Tipo $c$ o fractura simple de una masa lateral. Tipo $d$ o fractura conminuta de la masa lateral (el ligamento transverso del atlas está posiblemente dañado). Tipo e o verdadera fractura de Jefferson en la que los arcos anterior y posterior del atlas están fracturados bilateralmente (Fig. 3 A); Tipo $f$ con fracturas unilaterales a la vez del arco anterior y del arco posterior lineales o cruzadas y Tipo g que se asimila a la rotura aislada del ligamento transverso del atlas. Las fracturas Tipo e y algunas $d$ y $g$ son inestables. En las fracturas Tipo e puede producirse una separación lateral de ambas masas del atlas (Fig. 3 B). Según Spence ${ }^{84}$, si la suma de desplazamiento lateral de ambas masas es superior a $6.9 \mathrm{~mm}$. existe una muy alta probabilidad de que se asocie una ruptura del ligamento transverso convirtiendo a estas fracturas en altamente inestables. ( Fig. $3 \mathrm{C}$ ).

Los pacientes con fracturas aisladas del atlas que llegan al hospital casi nunca presentan síntomas neurológicos. Existen pocos datos para sospechar una fractura del atlas en los pacientes traumáticos que llegan al hospital inconscientes. En los pacientes lúcidos, el mecanismo del accidente, junto a la presencia de contractura y dolor cervical, limitación de los movimientos de la cabeza, dolor suboccipital, o anestesia o neuralgia occipital pueden orientar el diagnóstico. La presencia de un hematoma retrofaríngeo puede objetivarse o sospecharse ante la presencia de disfagia o disartria. Unos pocos casos pueden presentar síntomas o signos neurológicos mielorradiculares altos o por lesión de la arteria vertebral.

El diagnóstico se confirmará con las exploraciones de 
neuroimagen. Aunque en ocasiones podemos objetivar o sospechar una fractura del atlas en las RX simples, el mejor método de exploración para objetivar una fractura de $\mathrm{C} 1$ es la TAC con ventana ósea o la TAC 3 D. Los ligamentos, partes blandas, médula o arterias vertebrales se podrán ver bien con RNM o angio-RNM.

La gran mayoría de los casos diagnosticados precozmente pueden ser tratados con medios conservadores. Las ortesis cervicales tipo Philadelphia o SOMI pueden ser suficientes en la mayoría de estas lesiones. Las lesiones inestables recientes tipo $d$ y e pueden ser tratadas mediante la colocación de halos craneotorácicos entre 10 y 16 semanas $^{45}$. Algunos casos con desplazamientos de las masas de $\mathrm{C} 1$ podrán requerir alineación de la fractura con tracciones cervicales. Si se opta por el tratamiento inicial con métodos conservadores, los pacientes requerirán exhaustivos controles de neuroimagen evolutivos. A mi juicio es preferible proponer a los pacientes con claras lesiones inestables un tratamiento quirúrgico inicial mediante fijaciones instrumentadas occipitocervicales (Fig. 3) o fijaciones C1-C2 con reducción intraoperatoria en el caso de desplazamientos de estas fracturas. La cirugía estará indicada siempre en los pacientes a los que se les diagnostica una lesión inestable del atlas tardíamente. (Fig. 4).

\section{Fracturas del axis}

Representan hasta el $17 \%$ de todas las fracturas cervicales. De éstas, un 55\% son fracturas de la apófisis odontoides, un $23 \%$ son fracturas de los pedículos y un $22 \%$ asientan en el cuerpo del axis o en otras localizaciones menos frecuentes.

\section{Fracturas de la apófisis odontoides}

Es el tipo de fractura más frecuente de la columna cervical alta. La fractura de la base de la odontoides es tremendamente inestable y con una peligrosidad evolutiva potencial enorme si no se logra su consolidación. El manejo terapéutico de las fracturas crónicas de la base de la apófisis odontoides es totalmente distinto del de las fracturas agudas.

Se considera como aguda a aquella fractura con menos de 4 semanas de evolución desde el accidente.

La gran mayoría de los pacientes que hoy en día llegan a nuestros hospitales con fracturas de la apófisis odontoides (AO) están neurológicamente indemnes ${ }^{66,67,69,70}$. Sin embargo, es un tipo de fractura que puede producir la muerte por cizallamiento medular o graves lesiones neurológicas en el momento del accidente ${ }^{1}$. Puede aparecer clínica de mielopatía cervical tardía semanas, meses o
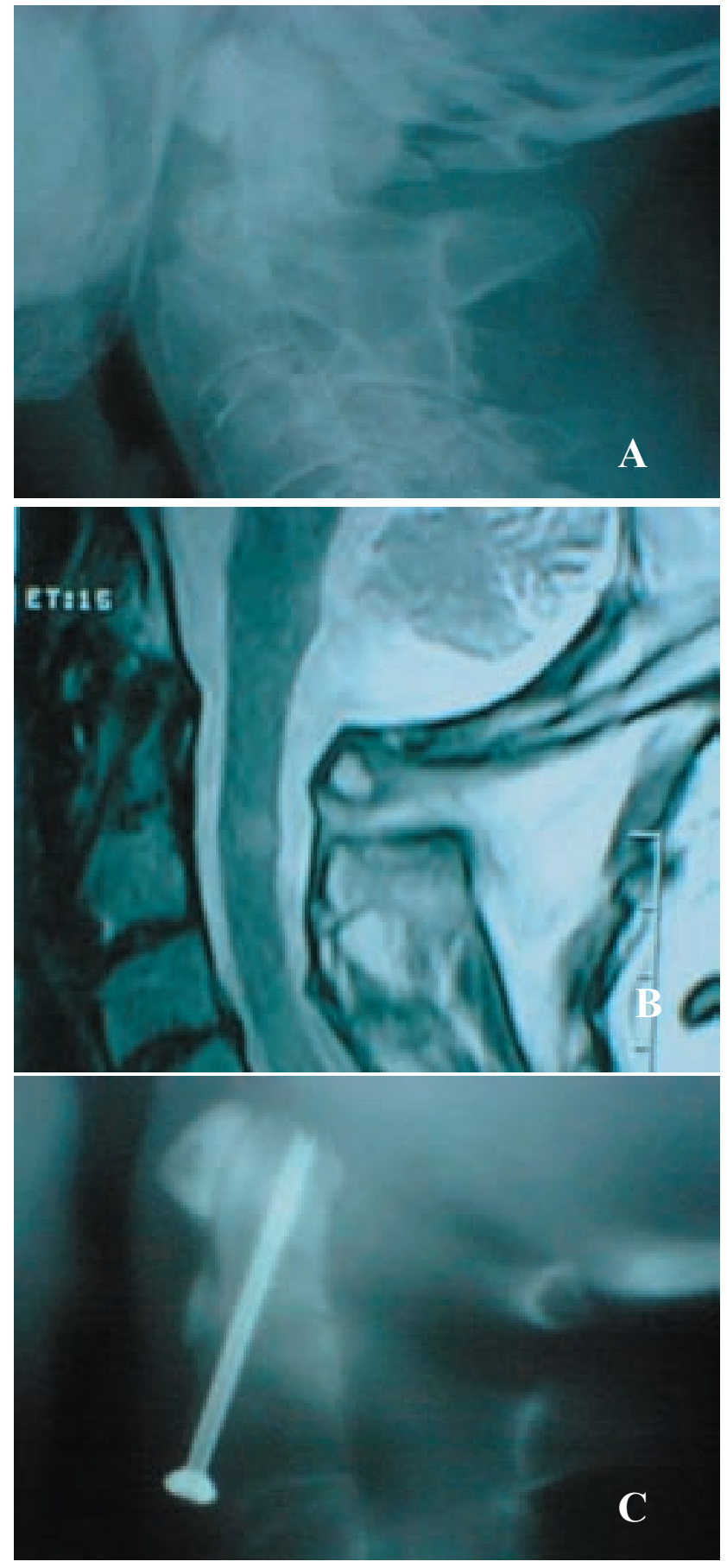

incluso años después de producirse la fractura ${ }^{8,22}$. Aquellos pacientes asintomáticos neurológicamente, que con un correcto tratamiento consiguen la reducción, fijación y fusión ósea de su fractura, consiguen la curación de estas graves lesiones $^{69}$. (Fig. 5).

En no pocas ocasiones estas fracturas pueden pasar desapercibidas y son diagnosticadas tardíamente, cuando ya existe una pseudoartrosis establecida, que indudablemente va a dificultar y complicar su tratamiento. Igual 

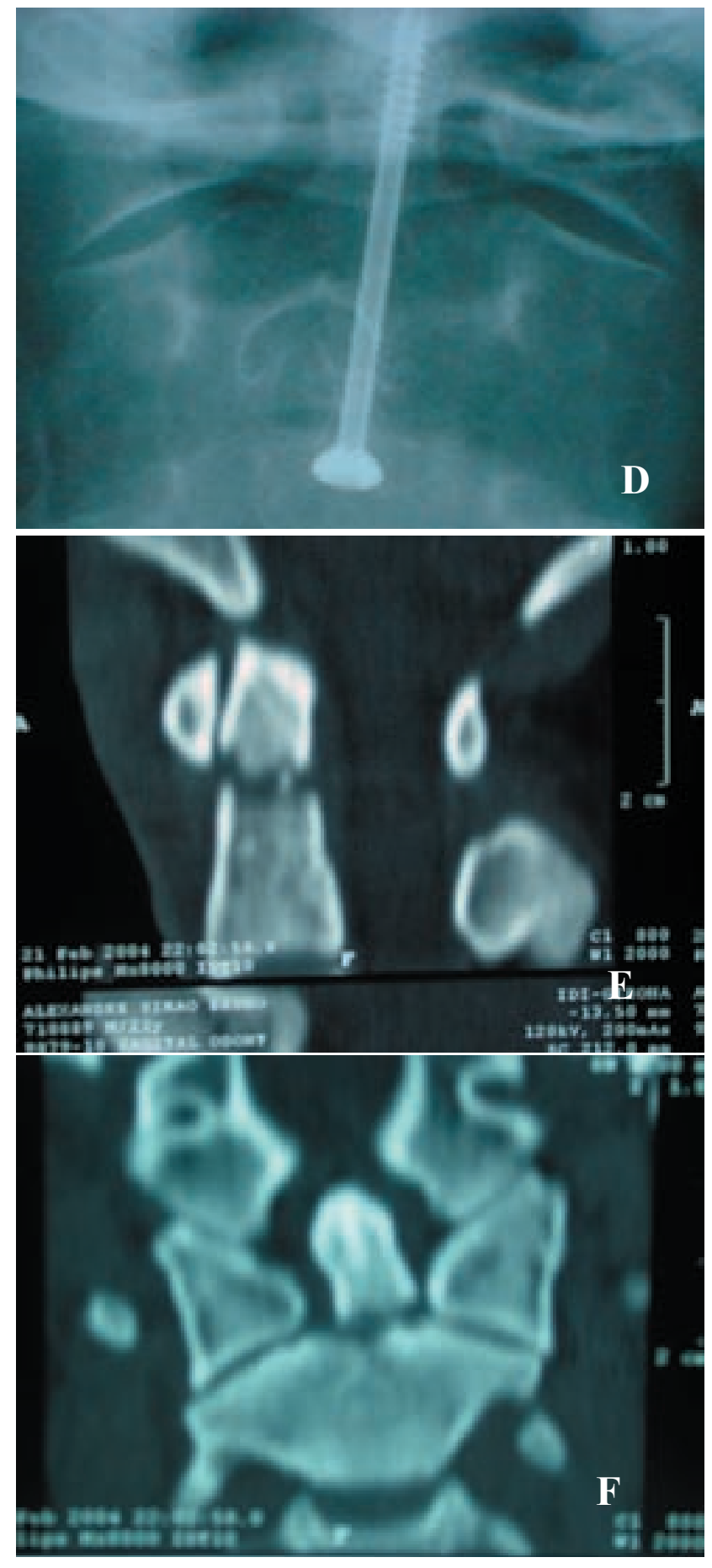

grado de dificultad existirá en los casos que no consiguen una correcta unión ósea con tratamientos iniciales no efectivos.

Las fracturas de la AO tienen que ser consideradas como una grave enfermedad con capacidad lesional evolutiva. Un correcto tratamiento en las fases iniciales puede conseguir la curación de estos pacientes. Un fracaso terapéutico o un retraso diagnóstico va a conllevar la necesidad
2006; 17: 391-419
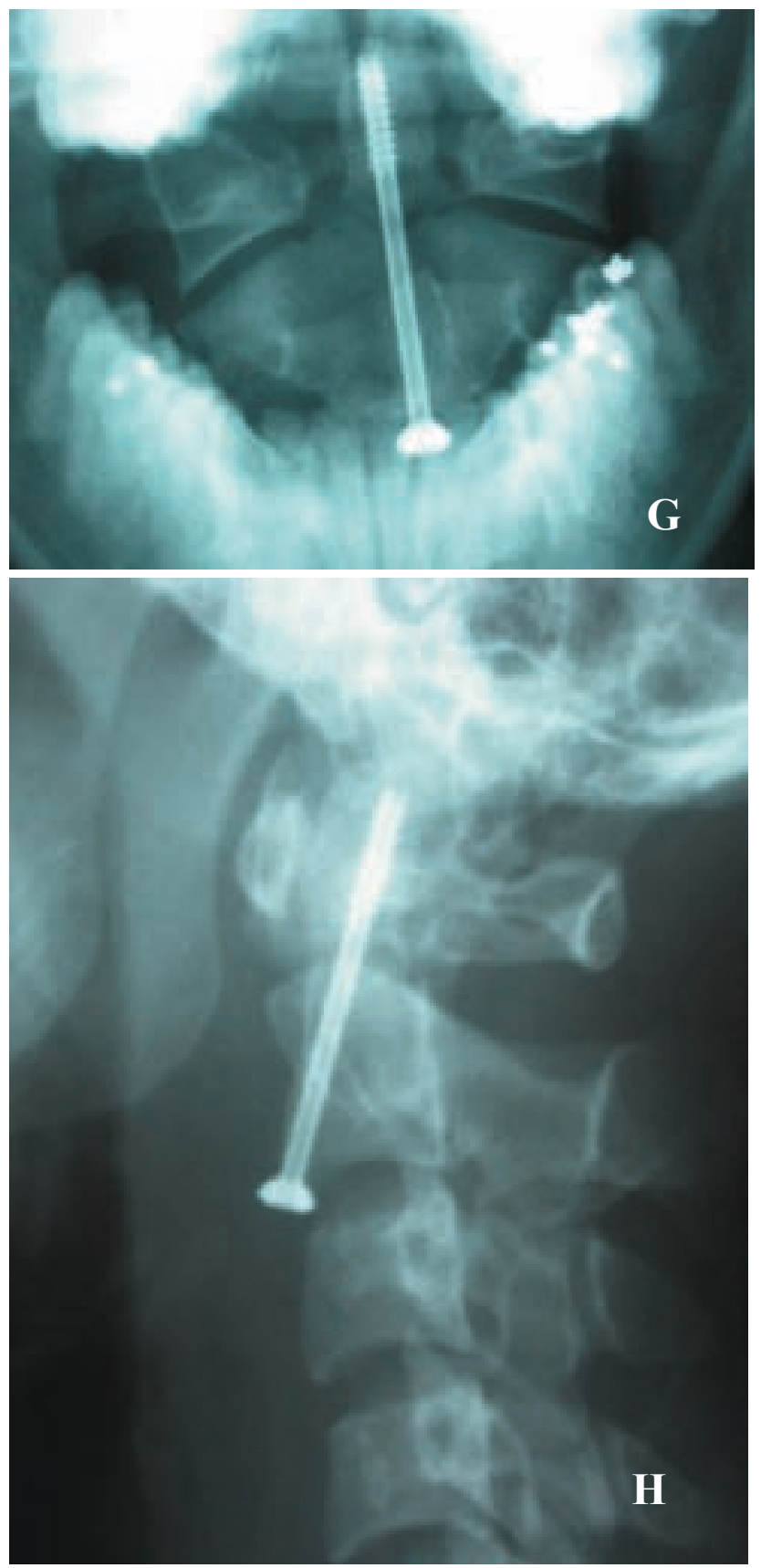

Figura 5. Fractura aguda de la base de la odontoides (IIP-10). (5A): $R X$ desplazamiento posterior de la apófisis odontoides. Asocia fractura arco posterior del atlas (5B): RNM cervical con fractura de la base de la odontoides reducida y fijada con tornillo. (5C) y (5D): $R X$ con atornillado anterior de la fractura.(5E-F-G-H):Fractura base odontoides, TAC preoperatorio, $R X$ postoperatoria.

de estrategias terapéuticas mucho más agresivas que siempre van a significar la pérdida de la importante función de este segmento. 
En las fracturas agudas de la AO también se aplican los principios fundamentales de tratamiento de cualquier fractura: reducción perfecta y precoz corrigiendo todas las desviaciones, inmovilización absoluta, adecuada, prolongada e ininterrumpida, y tratamiento funcional precoz, activo y persistente. Asimismo su tratamiento también debe regirse por el proceso biológico de formación del callo óseo, proceso sólo posible en las primeras tres o cuatro semanas tras el accidente.

En 1910, Mixter y Osgood ${ }^{73}$ y Pilcher ${ }^{77}$ publican las dos primeras referencias bibliográficas referentes al tratamiento quirúrgico de una fractura de la base de la AO. Se trataba de pacientes con fracturas antiguas con pseudoartrosis establecidas que impidieron su correcta reducción y a los que se les aplicó una artrodesis interlaminar C1-C2 con seda, obteniendo un buen resultado funcional y neurológico. A partir de esta fecha, y a lo largo de casi setenta años, las pautas de actuación terapéutica sobre estas fracturas se dirigen unánimemente a la descripción, elaboración y mejora de técnicas de contención ortopédica ${ }^{12,19,54,83}$, fijación posterior interlaminar $\mathrm{C} 1-\mathrm{C} 2{ }^{23,34,43,48,72}$, fijaciones interarticulares $\mathrm{C} 1$ $\mathrm{C}^{32,38,55,63,68,65}$ o resecciones de la $\mathrm{AO}^{22}$ (métodos indirectos).

En 1928, Osgood ${ }^{75}$ establece las bases teóricas de las pautas de actuación sobre estas fracturas. Afirma que siempre son fracturas graves, o al menos con un potencial de gravedad, y que deben ser reducidas e inmovilizadas lo más precozmente posible. En su trabajo hace referencia a que hasta esa fecha no se había descrito ningún tratamiento quirúrgico por vía anterior (método directo). Esta última aseveración nos parece esencial, pues este concepto de posibilidad terapéutica directa sobre el foco de fractura no fue recogido y aplicado hasta 1979 por Nakanishi ${ }^{74}$ y Böhler ${ }^{16}$, habiendo transcurrido casi un siglo para que se modificase conceptualmente la necesidad del tratamiento directo anterior sobre el foco de fractura de la base de la AO.

A lo largo del siglo pasado las pautas de clasificación y manejo terapéutico de la fracturas de la AO se han mantenido, cuanto menos, controvertidas.

\section{Diagnóstico}

La gran mayoría de las fracturas de la AO pueden y deben ser diagnosticadas mediante estudios radiológicos simples tras el accidente; las radiografías en proyecciones anteroposterior y lateral nos mostrarán la línea de fractura así como sus posibles desplazamientos. Esta exploración puede completarse mediante estudios con TAC y RNM, para valorar posibles lesiones ligamentosas u óseas asociadas y el estado de la médula.

\section{Clínica}

La gran mayoría de las fracturas de la $\mathrm{AO}$ sólo presentan dolor cervical y cierto grado de impotencia funcional para los movimientos de la cabeza. Menos del 6\% de casos se presentan en el hospital con clínica neurológica. Sin embargo dos de nuestros pacientes $(2.56 \%)$ ingresaron en el hospital con graves tetraplejias y disfunción respiratoria que les ocasionaron la muerte.

\section{Clasificación}

Aunque se han descrito diversos modelos de clasificación de las fracturas de la $\mathrm{AO}^{2,30,36,43,80,81}$, todavía y desde hace más de 30 años se usa, casi unánimemente, la clasificación de las mismas propuesta por Anderson y D'Alonzo ${ }^{3}$ en 1974. Para estos autores existen tres tipos de fracturas: el Tipo I, que representa una fractura del vértex de la AO; el Tipo II, donde la fractura cruza la base de la odontoides cuando ésta se une al cuerpo del axis y el Tipo III, en que la fractura se extiende al cuerpo del axis. Más del $60 \%$ de fracturas de la AO corresponden al tipo II. En 1988, Hadley ${ }^{45}$ añade un nuevo tipo de fractura que se corresponde con fracturas conminutas de la base y que denomina Tipo IIA.

Geisler $^{36}$ divide a las fracturas tipo II de Anderson y D'Alonzo en Tipo II-A, Tipo II-N y Tipo II-P según que el desplazamiento de la AO sea anterior, neutro o posterior en relación al cuerpo del axis. Nosotros utilizamos esta subclasificación de las fracturas de la base de la AO a efectos nosográficos y descriptivos de cada fractura, pero añadimos un número final que nos indica los milímetros de desplazamiento en cada momento ${ }^{67,69}$ (Tipo II-A-3, Tipo II-P-9, Tipo II-N,...).

Dado que las fracturas Tipo III de la clasificación de Anderson y D'Alonzo no son verdaderas fracturas de la AO, sino fracturas transversas del cuerpo del axis, nosotros en 1997 propusimos una nueva clasificación en dos tipos $^{69,71}$ : Fracturas del ápex y Fracturas de la base. Las primeras pueden manejarse mediante métodos conservadores de contención ortopédica, y las segundas que consideramos siempre inestables, deben ser tratadas inicial e idealmente mediante su osteosíntesis anterior, reservando los otros métodos indirectos de tratamiento cuando fracase su osteosíntesis directa o bien en el caso de su diagnóstico tardío.

Las fracturas de la base de la AO representan más del $55 \%$ de las fracturas de $\mathrm{C} 2$, siendo las lesiones traumáticas más frecuentes del axis. Su escasa expresividad clínica y posibilidad de ausencia de desplazamiento inicial, obliga a los servicios de urgencias hospitalarios a descartar su existencia en todos aquellos pacientes traumáticos inconscientes o con mecanismos lesivos que sugieran su existencia. 
Material: Fracturas agudas de la AO

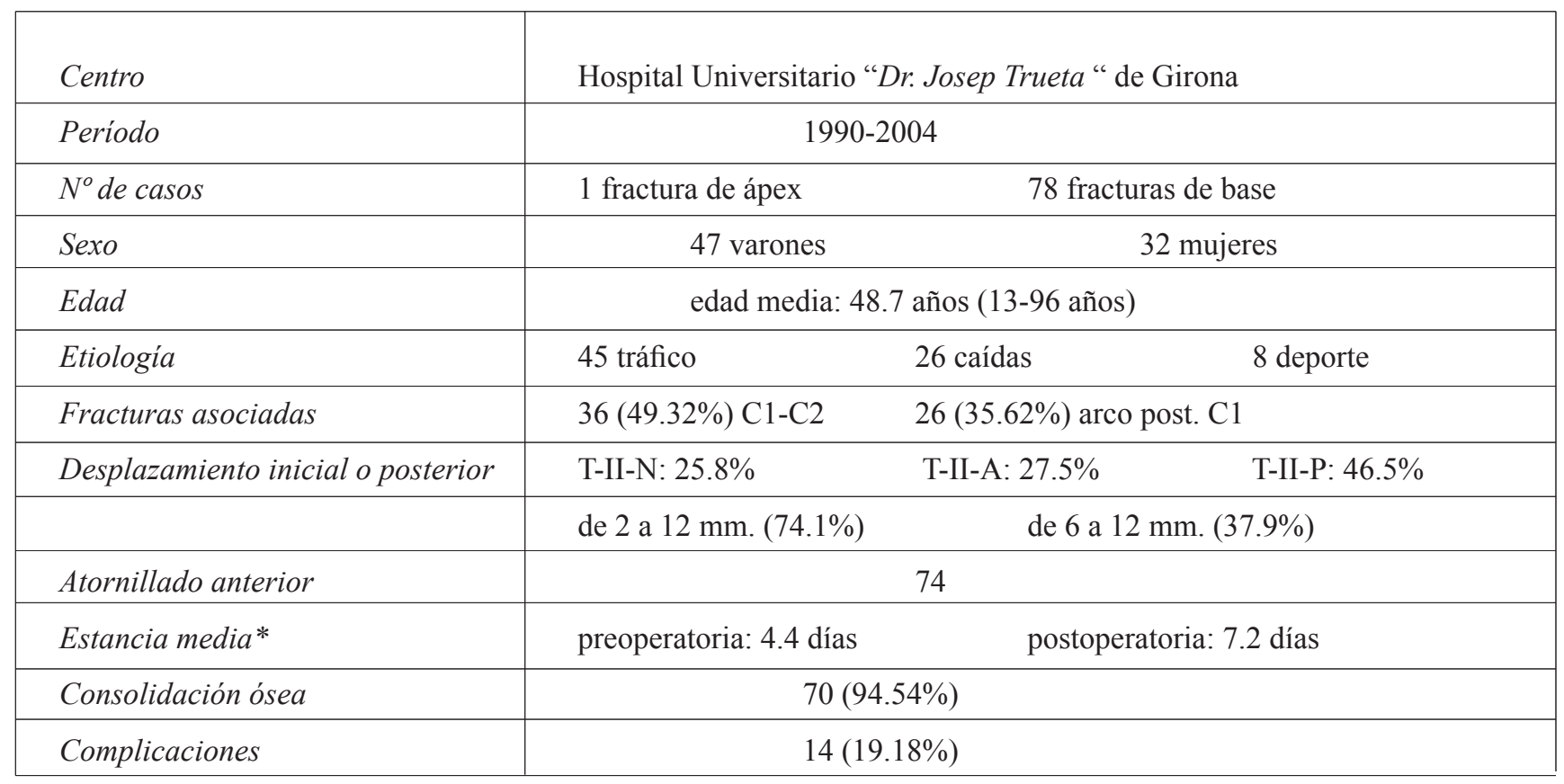

* Incluye casos extremos (patología asociada, ingresos en UCI, ....)

\section{Tratamiento}

Resulta obvio que el principal objetivo del tratamiento de una fractura de la $\mathrm{AO}$ es conseguir lo antes posible, y de la forma más cómoda para el paciente, su consolidación ósea, respetando la función biomecánica del complejo atloaxoideo y las estructuras vasculonerviosas cercanas. En 1985 la Cervical Spine Research Society ${ }^{21}$ publica un estudio multicéntrico en el que concluyen que todas las fracturas de la AO deben ser tratadas, pues la abstención terapéutica siempre conlleva la ausencia de fusión.

Según nuestro criterio, hay que relegar a un segundo plano de selección terapéutica aquellos métodos que, por actuar a distancia del foco de fractura, impiden una inmovilización absoluta o bien reducen, de entrada, la funcionalidad del complejo C1-C2. Creemos firmemente que, reducir lo mejor posible y con la mayor precocidad una fractura de la base de la $\mathrm{AO}$, inmovilizarla completamente actuando directamente sobre el foco de fractura, y no interferir sobre los elementos ligamentosos, articulares y musculares del complejo que la rodea, es el método terapéutico ideal que inicialmente debemos ofrecer a todos los pacientes con este tipo de fractura.

\section{Métodos indirectos}

Son aquéllos que actúan a distancia del foco de la fractura. Tradicionalmente se han usado técnicas conservadoras, como diversos tipos de ortesis cervicales, compás de tracción o halos craneotorácicos y técnicas quirúrgicas de artrodesis interlaminares $\mathrm{C} 1-\mathrm{C} 2$, fijaciones occipitocervicales o interarticulares $\mathrm{C} 1-\mathrm{C} 2$ anteriores o posteriores, resecciones de la $\mathrm{AO}$ o técnicas combinadas. La aplicación práctica de un tipo u otro de estas técnicas ha estado condicionada atendiendo a numerosos factores de selección terapéutica no coincidentes entre los diversos autores, y no se ha logrado establecer nunca pautas de actuación uniformes y universalmente aceptadas. Un importante grupo de pacientes tratados con estos métodos indirectos no consigue su curación. Así, con ortesis cervicales la tasa de fusión es del $57 \%{ }^{78}$, con halos craneotorácicos del $70 \%{ }^{58}$; un número muy importante de pacientes presentan pseudoartrosis del foco de fractura con estos métodos de tratamiento, lo que implica cronificación de la fractura y necesidad de cirugías posteriores. Con fusiones posteriores, la tasa de estabilización/fusión se acerca al $100 \%$ pero a costa del sacrificio funcional atloaxoideo de entrada. Las fracturas Tipo I consiguen fusiones cercanas al 100\% con métodos de tratamiento indirectos conservadores.

\section{Método directo}

La osteosíntesis anterior de las fracturas agudas de la base de la AO mediante su atornillado, descrita por Böhler y Nakanishi en 1981, nos parece el método inicial e ideal de tratamiento de todas estas fracturas. Cumple todos los requisitos traumatológicos de tratamiento de una fractura, obtiene consolidación ósea en la gran mayoría de los casos ( $>90 \%$ ), respeta la funcionalidad atloaxoidea, y tras un cuidadoso aprendizaje y meticulosidad en su aplicación 
no presenta más dificultad técnica que cualquier abordaje cervical anterior. Hoy en día ningún paciente tributario de esta técnica debería ser tratado inicialmente mediante técnicas indirectas que consiguen menor porcentaje de consolidación ósea o que de entrada reducen la funcionalidad atloaxoidea.

\section{Factores de selección terapéutica}

\section{Edad}

Algunos autores consideran que la edad es un factor condicionante que contraindica el atornillado anterior de las fracturas de la base de la AO por encima de los 65 años $^{6,47}$. Tal suposición ha sido rebatida tanto por nuestra experiencia como por otros autores. A nuestro juicio, la osteosíntesis anterior en pacientes añosos es el mejor método de tratamiento posible, ya que con una intervención quirúrgica relativamente poco agresiva, se evitan largos períodos de encamamiento, se facilita rápidamente la movilización del paciente sin apenas soportes externos $\mathrm{y}$, a nuestro parecer, es una técnica mucho menos agresiva que los abordajes posteriores o someter a pacientes añosos bajo halo por prolongados períodos de tiempo. Consideramos que no existe contraindicación para el atornillado anterior de la odontoides por encima de los 12 años, fecha en que se produce la consolidación fisiológica de la $\mathrm{AO}$ al cuerpo del axis. Sin embargo, recientemente se han publicado trabajos en que se han efectuado osteosíntesis de estas fracturas en pacientes a partir de los tres años de edad. De este modo el rango de indicación para estas osteosíntesis queda establecido en la literatura desde los 3 a los 95 años $^{37,57,59}$. En nuestra serie de 73 fracturas el rango de edad es de 13 a 96 años.

\section{Desplazamiento}

Tras su fractura, y dependiendo del mecanismo biomecánico de su producción, la AO puede desplazarse anterior, posterior y/o lateralmente en relación al cuerpo del axis, con diversos grados de angulación o de separación del cuerpo. La magnitud del desplazamiento $(>4-6 \mathrm{~mm}$.) y su dirección condiciona para algunos autores la elección del método de tratamiento, ya sea conservador o quirúrgico, según su estabilidad o reductibilidad. A mi entender todas las fracturas de la base de la $\mathrm{AO}$ son fracturas inestables y el grado de desplazamiento objetivado radiológicamente en un momento determinado puede variar de un momento a otro en nuevos y sucesivos estudios radiológicos (factor dinámico). He objetivado redesplazamientos incluso en pacientes inmovilizados inicialmente con halos. No he tenido dificultad alguna para reducir adecuadamente las AO desplazadas con maniobras intraoperatorias en la gran mayoría de los casos. La estabilidad final se consigue con la inmovilización de los fragmentos tras su atornillado anterior.

\section{Fracturas asociadas}

Alrededor de un $40 \%$ de las fracturas de la AO se asocian a otras fracturas del complejo C1-C2 $2^{29,44}$. De éstas un $20 \%$ corresponden a fracturas del arco posterior de $\mathrm{C} 1$, impidiendo la aplicación de técnicas de fijación interlaminares, al menos en fases precoces. Según nuestro criterio, las fracturas asociadas a una fractura de la base de la AO no condicionan su atornillado anterior. Cada fractura debe analizarse individualmente y aplicar concomitantemente el tratamiento quirúrgico o conservador que requiera cada una de ellas.

\section{Linea de fractura}

El trazo de la línea de fractura de la AO puede ser horizontal, oblicuo anterior u oblicuo posterior. Muy pocos casos presentan un trazo conminuto (5\%). Únicamente se contraindica el atornillado anterior en aquellas fracturas oblicuas con línea de fractura de atrás hacia adelante y de arriba hacia abajo por su inestabilidad biomecánica tras el atornillado, a no ser que se añada a la osteosíntesis algún sistema de contención antideslizante de la odontoides.

\section{Integridad ligamentosa}

La ruptura concomitante del ligamento transverso del atlas provoca una grave inestabilidad atloaxoidea que contraindica el atornillado anterior de una fractura de la base de la AO. A mi juicio estas lesiones precisan de una fijación posterior transarticular o interarticular $\mathrm{C} 1-\mathrm{C} 2$ asociada a una fijación interlaminar C1-C2.

\section{Malformaciones congénitas}

En la literatura revisada no hemos encontrado ningún caso que asocie una fractura de la base de la $\mathrm{AO}$ a algún tipo de malformación congénita del complejo atloaxoideo. En nuestra casuística un paciente presentaba una agenesia parcial del atlas y otro un bloque congénito C2-C3 asociados a su fractura de la base de la AO. Estas malformaciones no condicionaron la osteosíntesis anterior de la odontoides fracturada, si bien en el segundo caso tuvimos que utilizar un largo tornillo desde la base de C3 hasta el vértex de la odontoides.

\section{Tiempo de evolución}

En nuestra opinión, el atornillado directo de una fractura de la $\mathrm{AO}$ no debe demorarse más allá de las cuatro semanas. Cuanto más reciente es una fractura más fácil es su reducción intraoperatoria. La inmovilización del foco de fractura debe realizarse antes de que se inicien los mecanismos fisiopatológicos de producción de la pseudoartrosis. No obstante Apfelbaum ${ }^{5}$ refiere consolidaciones en un 25\% de los casos atornillados entre los 6 y 18 meses después del accidente. 


\section{Método}

Todos los pacientes ingresados en nuestro servicio con fracturas agudas de la base de la $\mathrm{AO}$ son candidatos a una osteosíntesis anterior de su fractura, independientemente de la existencia o no de desplazamiento en su diagnóstico radiológico inicial o posterior, de la edad del paciente, de malformaciones u otras fracturas asociadas o de su situación neurológica. La cirugía se realiza tan precozmente como lo permite la situación general del paciente en relación a posibles lesiones asociadas. Si existe algún tipo de fractura de atlas o axis asociada y tributaria también de tratamiento quirúrgico, éste se realiza en el mismo tiempo quirúrgico.

Hemos utilizado un compás de tracción en seis de los 78 casos tratados. Se trataba de pacientes con desplazamientos superiores a los $6 \mathrm{~mm}$. y con síntomas neurológicos mielorradiculares. Únicamente en 14 pacientes se ha demorado la cirugía más allá de las tres semanas. Consideramos que la reducción de la fractura es factible manualmente en el acto operatorio. Nunca hemos utilizado halos craneotorácicos en el manejo de estas fracturas.

La técnica quirúrgica que utilizamos es la descrita por Nakanishi y Böhler. La cabeza del paciente se apoya sobre un soporte de Mayfiel sin estar fijada, esto permite las maniobras de reducción bajo radioscopia. Siempre utilizamos doble radioscopia en proyecciones anteroposterior y lateral. Nunca iniciamos la intervención hasta que visualizamos muy correctamente el axis en esa doble proyección radiológica y comprobamos la reductibilidad manual de la fractura. Nuestros últimos 12 casos han sido intervenidos a través de pequeñas incisiones de $2 \mathrm{~cm}$. al utilizar cánulas de trabajo que permiten todas las maniobras de la instrumentación a través de ellas mediante técnicas mínimamente invasivas (guía de McGuire) ${ }^{60}$. Últimamente se han descrito atornillados mediante técnicas endoscópicas ${ }^{51,52,53}$. Aunque inicialmente la técnica se describió con el uso de dos tornillos, diversos trabajos biomecánicos y morfométricos aconsejan el uso de un sólo tornillo. Tras la intervención el paciente inicia la deambulación a las 24 horas con una ortesis cervical blanda o Philadelphia si sólo existe una fractura de la AO aislada, o tipo SOMI o Minerva moldeada si además hay fracturas de atlas o axis asociadas y que mantenemos de cuatro a seis semanas.

\section{Resultados}

De los 74 casos atornillados por el autor se ha conseguido una consolidación de la fractura de la base de la AO (unión ósea), demostrada radiológicamente, en 70 casos (94.54\%). A nuestro entender, la cuantía, tipo y grado de luxación de la $\mathrm{AO}$ no condiciona el resultado, para nosotros es sólo un factor de mayor o menor dificultad técnica a la hora de su reducción intraoperatoria. La consolidación se ha obtenido con una correcta alineación de la $\mathrm{AO}$ en 54 casos (71.64\%); 20 pacientes $(28.35 \%)$ han obtenido una fusión con cierta anteversión o retroversión, de la AO, aunque esta situación no modifica una correcta funcionalidad del complejo atloaxoideo ${ }^{20,71}$. La exploración neurológica es normal en 63 casos (83.56\%).

En la mayoría de las series publicadas en los últimos 80 años se describe un considerable número de fracasos en el tratamiento de las fracturas de la base de la AO independientemente de los métodos indirectos utilizados ${ }^{21,45,58,78}$. Entre otros se han implicado factores de déficit vascular o diferenciación trabecular deficitaria en la base de la AO para explicar estos fracasos ${ }^{82}$. En este período la mayoría de los pacientes han sido tratados mediante métodos conservadores o artrodesis posteriores. Según la literatura, el índice de fracasos de consolidación con el uso de ortesis cervicales oscila del 15 al $100 \%$ de los casos; los pacientes tratados mediante halo craneotorácico o compás de tracción no superan el $60 \%$ de consolidación ósea y los tratados mediante artrodesis posteriores obtienen de un 20 a un $100 \%$ de consolidación.

\section{Complicaciones}

En nuestra serie 14 pacientes (18.91\%) han presentado algún tipo de complicación. El número y tipo de complicaciones se corresponden con los publicados en la literatura ${ }^{7}$. Estas complicaciones se presentaron en nuestros primeros casos intervenidos relacionado, entre otros factores, con nuestra curva de aprendizaje. Se han constatado cuatro pseudoartrosis del foco de la fractura, dos de ellas precisaron nueva estabilización mediante fijaciones posteriores, y otras dos con uniones fibrosas totalmente funcionales y con ausencia de movilidad del foco de la fractura siguen controles exhaustivos evolutivos, sin que hasta ahora se considere que precisan nuevas actuaciones quirúrgicas. Para nosotros, esta unión fibrosa, fibrous union de la literatura anglosajona, no representa en ningún caso la resolución definitiva del problema. Un caso presentó una lesión protuberancial en relación a las maniobras de instrumentación por migración craneal inadvertida de una aguja de Kirschner durante la cirugía. Dos precisaron traqueostomías en el postoperatorio inmediato por edema cervical de partes blandas. Tres casos precisaron ser reintervenidos en el mismo ingreso hospitalario por malposición primaria del tornillo en la primera osteosíntesis sin ninguna consecuencia neurológica ni funcional. Un caso precisó retirar el tornillo de la osteosíntesis seis meses después de la cirugía, tras constatar la consolidación de la fractura, por demasiada protrusión del tornillo en el ápex de la AO. Un sólo paciente de 84 años, atornillado por el autor en otro hospital, falleció por complicaciones cardiorrespiratorias 
Neurocirugía

Traumatismos de la columna cervical alta: Clasificación tipológica, indicaciones terapéuticas y abordajes quirúrgicos ....

2006; 17: 391-419
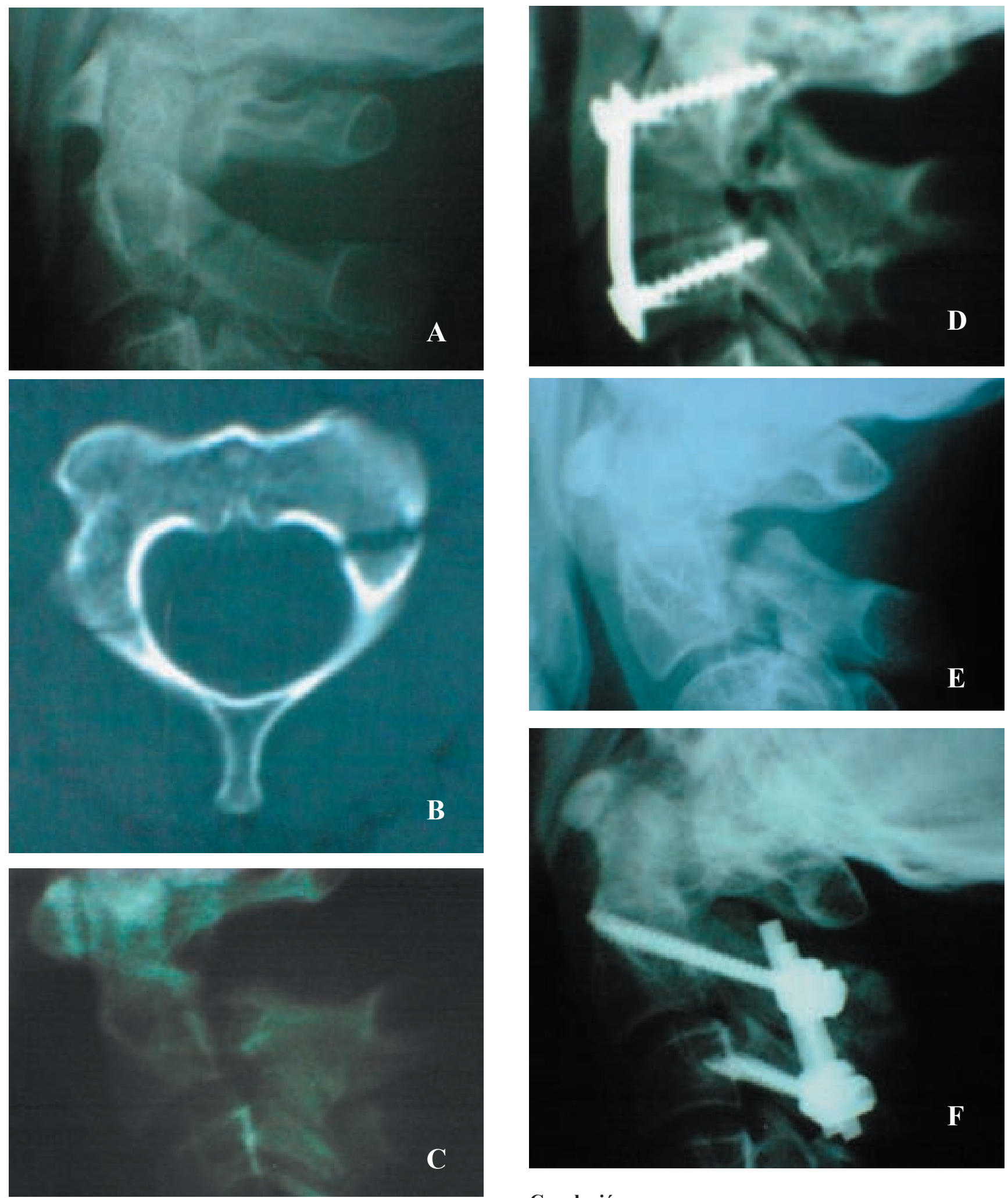

varios días después de la cirugía sin relación directa con este procedimiento.
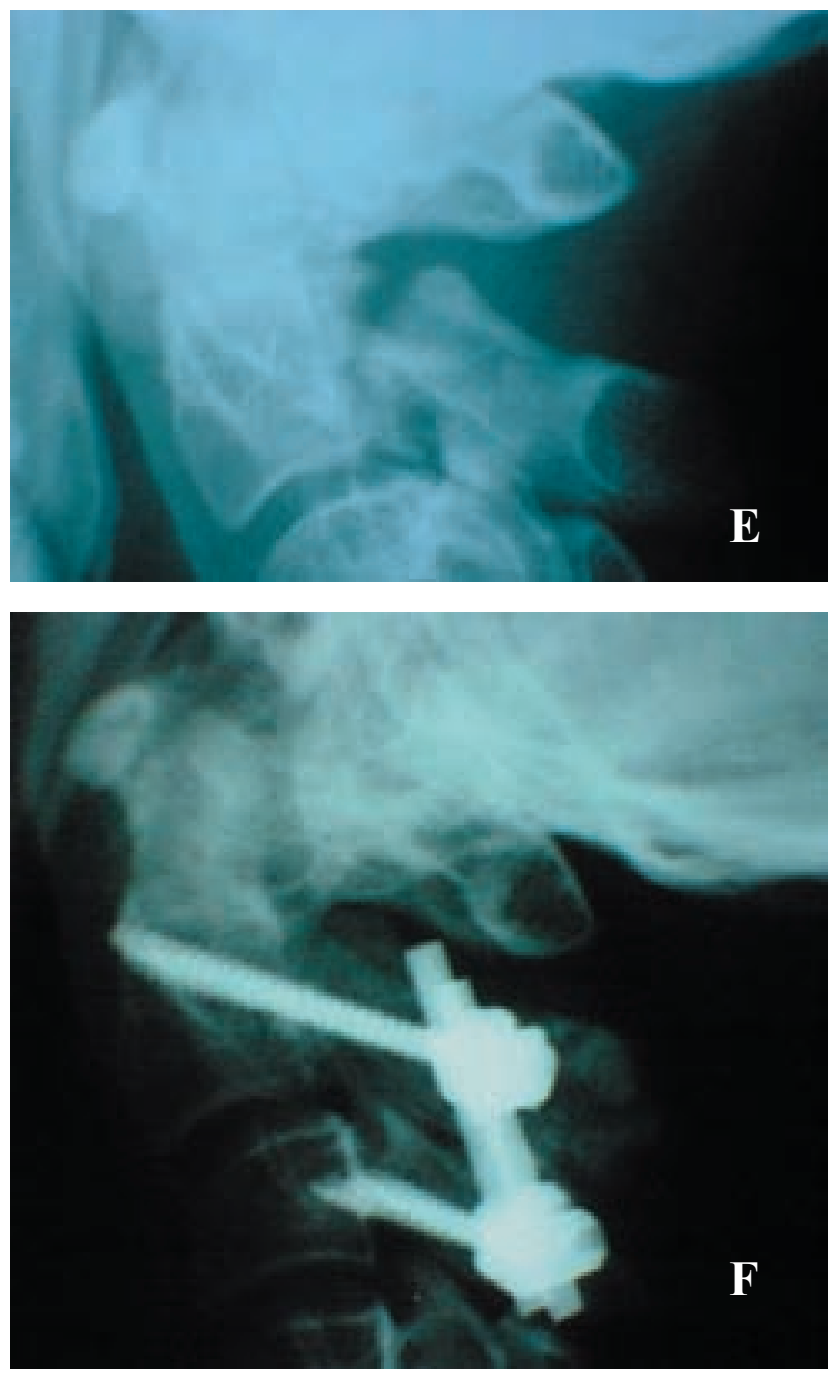

\section{Conclusión}

Las fracturas de la $\mathrm{AO}$ pueden clasificarse en fracturas del ápex y en fracturas de la base. 

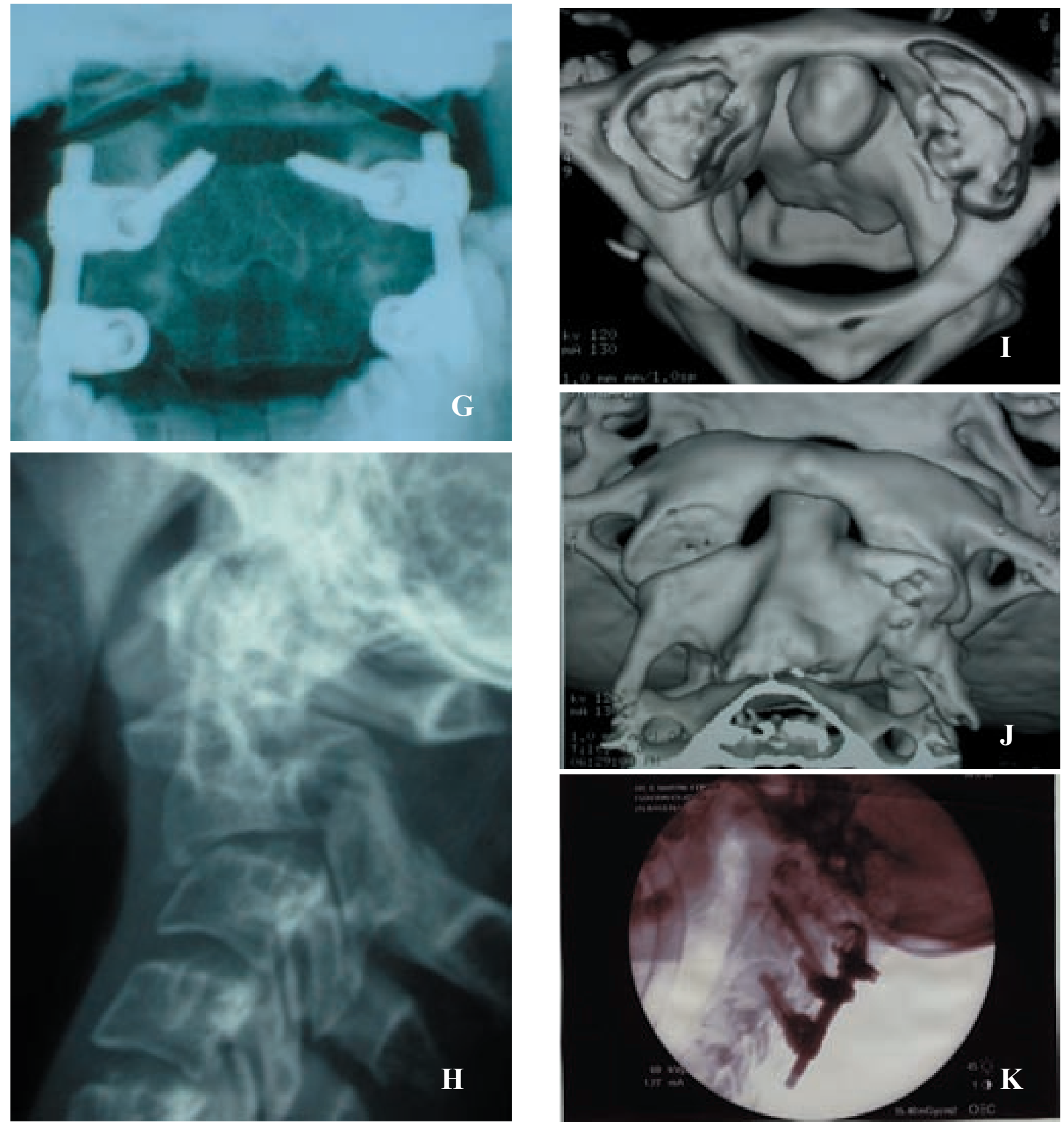

Figura 6. Fracturas pediculos de C2. (6A) y (6B): $R X$ y TAC de C2, fractura tipo I estable. (6C) y (6D): $R X$ con fractura tipo II inestable y fijación anterior C2-C3 con placa, tornillos e injerto óseo autólogo. (6E) (6F) y (6G): RX con fractura tipo II inestable y fijación posterior C2-C3. En AP nótese la indemnidad de las articulaciones C1-C2 . (6H-I-J-K): Fractura pediculos de C2 tipo IIa con rotación del cuerpo de C2.

En la última década aparecen numerosos trabajos publicados en que los índices de fusión de estas fracturas mejoran sustancialmente siempre en relación al abordaje directo del foco de la fractura de la base de la AO mediante su osteosíntesis anterior con tornillos ${ }^{91}$, obteniéndose resultados más uniformes, siempre por encima del $90 \%$, con escasa morbilidad y ausencia de mortalidad relacionada directamente con la técnica. 
Hace 75 años se sugirió la técnica del atornillado anterior de la odontoides y hace 25 años se describió la osteosíntesis anterior de las fracturas agudas de la base de la AO. A lo largo de estos años se ha demostrado un progresivo interés por la misma; dados los resultados publicados, y basándonos en la evidencia de nuestra propia experiencia clínica, consideramos firmemente que esta técnica es el método inicial e ideal de elección en la gran mayoría de los pacientes afectos de fracturas de la base de la $\mathrm{AO}^{69,70,71}$. Junto a las prótesis discales es la única cirugía de instrumentación sobre la columna cervical que mantiene totalmente la función del segmento intervenido.

\section{Fracturas de los pedículos del axis}

Las fracturas que asientan en los elementos posteriores de la segunda vértebra cervical se conocen también con la denominación de fractura de la "pars interarticularis", espondilolistesis traumática del axis o fractura de hangman. Es un tipo de fractura que, en su mayor expresividad, se presenta en los reos condenados a la horca, fractura que en estos casos se asocia a una brutal luxación C2-C3 por un mecanismo de hiperextensión-distracción. También puede presentarse por un mecanismo de hiperextensión-compresión en accidentes de circulación o caídas.

El objetivo en las fracturas de hangman provocadas por ahorcamiento es la muerte del reo por cizallamiento medular y de las arterias vertebrales. En las demás fracturas el tipo de manifestaciones neurológicas puede ser muy variable, aunque normalmente con poca expresividad. En la mayoría de casos sólo existe dolor cervical y en menos de la mitad neuralgia occipital por irritación de la raíz C2. Muchas de estas fracturas se asocian a traumatismos craneoencefálicos.

Se han propuesto distintos esquemas de clasificación de estas fracturas ${ }^{27,33,76}$. Actualmente se utiliza la clasificación de Levine y Edwards ${ }^{64}$ descrita en 1985. Según estos autores estas fracturas pueden dividirse en cuatro tipos: Tipo I, en donde la fractura pasa a través de la base del pedículo con $<$ de $3 \mathrm{~mm}$. de separación y sin angulación C2-C3 (Fig. 6 A-B ); Tipo II, en donde la separación de los fragmentos del pedículo es $>$ a $3 \mathrm{~mm}$. y existe una angulación entre $\mathrm{C} 2-\mathrm{C} 3<\mathrm{a} 11^{\circ}$ (Fig. $6 \mathrm{C}-\mathrm{E}$ ) ; Tipo IIa con grave angulación entre $\mathrm{C} 2-\mathrm{C} 3$, posibilidad de luxación de las facetas de estas vértebras y fractura oblicua de la "pars interarticularis" (de borde anteroinferior a borde posteroinferior); El Tipo III es la verdadera fractura del ahorcado con fractura del arco de C2 y separación-luxación C2-C3.

Las fracturas de los pedículos del axis se presentan como fracturas aisladas en un $74 \%$ de los casos.

La gran mayoría de las fracturas de los pedículos del axis podrán fusionar al ser tratadas con métodos conser- vadores mediante ortesis cervicales, Minervas moldeadas o halos craneotorácicos. Únicamente un pequeño grupo de pacientes afectos de fracturas tipo IIa, o con fracaso tras tratamientos conservadores, precisarán tratamiento quirúrgico.

A mi juicio las fracturas Tipo I y Tipo II deben ser tratadas inicialmente con medios conservadores mediante Minervas moldeadas occipitocervicales de 4 a 6 semanas. A estos pacientes se les efectúan estudios radiológicos funcionales a las 4-6 semanas y luego, ya sin ortesis, a las 6-8 semanas para comprobar la correcta fusión anatómica y funcional de la fractura. En caso de pseudoartrosis o en las fracturas Tipo IIa se indica un tratamiento quirúrgico. Nuestros primeros casos con indicación quirúrgica fueron tratados mediante artrodesis anterior con injerto autólogo intersomático y placa atornillada C2-C3 (Fig. 6 D), aunque en los últimos años preferimos efectuar fijaciones posteriores mediante tornillos y barras entre $\mathrm{C} 2$ y C3 (Fig. 6 F-G). Nunca hemos efectuado atornillados directos de la fractura como propone Borne ${ }^{18}$.

Siempre debe mantenerse la función de las articulaciones atloaxoideas. Los tornillos en $\mathrm{C} 2$ deben dirigirse hacia el cuerpo de C2 sin atravesar la articulación C1-C2. (Fig. 6 $\mathrm{G})$

En nuestra serie de 41 casos de fracturas de los pedículos del axis hemos conseguido su fusión ósea en el $100 \%$ de los casos, sólo 19 casos han precisado cirugía. Ninguno de nuestros pacientes han sido sometidos a tracciones cervicales ni han requerido halo.

Un grupo muy pequeño de pacientes van a presentar fracturas aisladas de la lámina, apófisis espinosa o alguna faceta del axis. Son fracturas estables y que sólo precisan tratamiento ortésico simple.

\section{Fracturas del cuerpo del axis}

En 1994, Benzel ${ }^{13}$ clasifica las fracturas del cuerpo del axis en tres tipos: fractura coronal o Tipo I, fractura sagital o Tipo II y fractura transversa o Tipo III.

La fractura tipo III de Benzel se corresponde con la fractura tipo III de la clasificación de las fracturas de la AO de Anderson y D'Alonzo; dado que son fracturas del cuerpo del axis más que de la $\mathrm{AO}$ consideramos que el tipo III de estos últimos autores no tiene razón de existir.

El Tipo III o fracturas transversas son las más frecuentes, seguido de las sagitales y de las coronales respectivamente.

En nuestra casuística de 27 fracturas transversas, 11 han precisado una fijación cervical posterior instrumentada, seis por inestabilidad y cinco por dolor cervical persistente al extenderse la línea de la fractura hacia las superficies articulares de $\mathrm{C} 2$. Únicamente una fractura sagital con separación medial del cuerpo del axis precisó un atorni- 

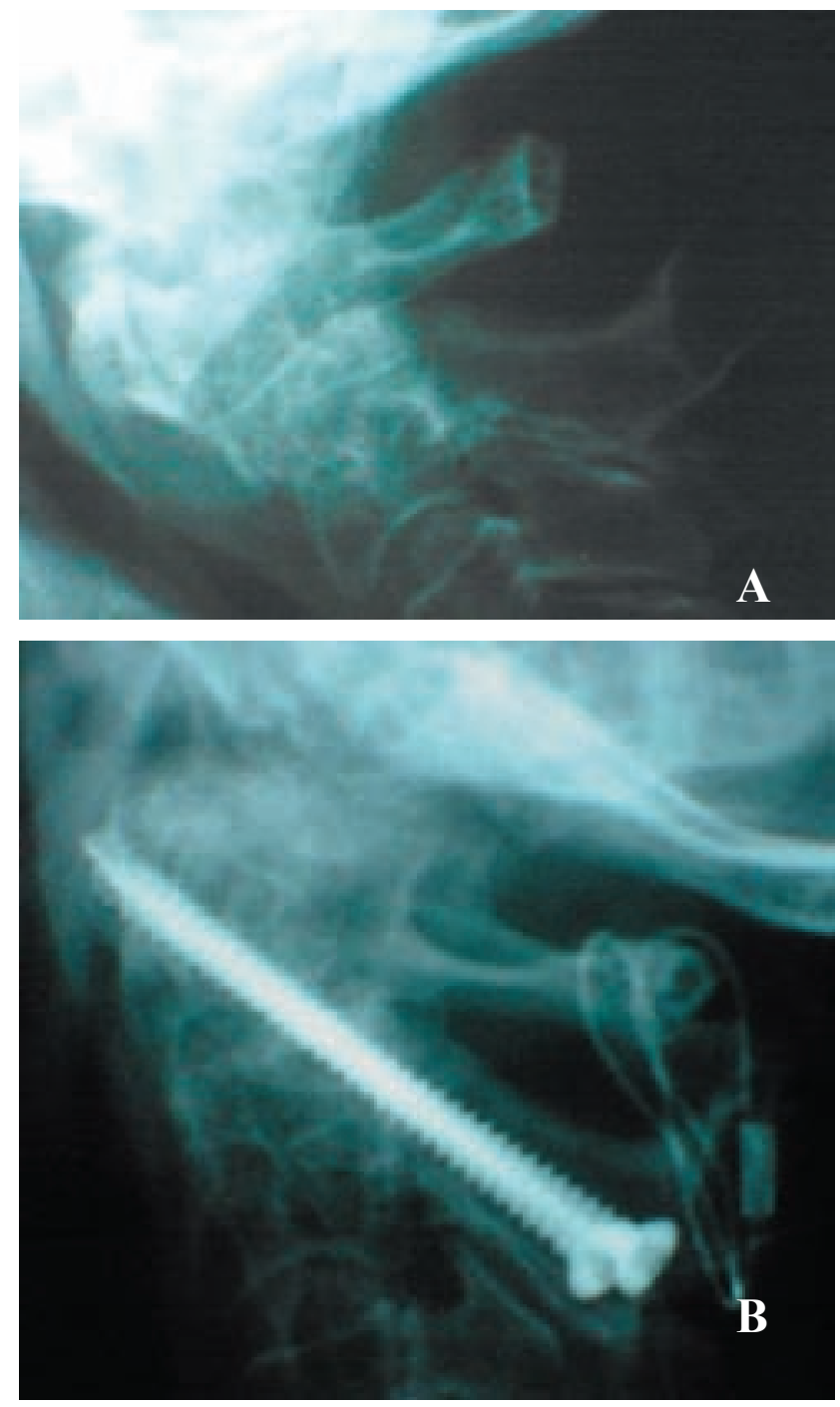

llado anterolateral del cuerpo de C2. Los restantes 14 casos con fracturas sagitales o coronales fueron tratados conservadoramente con Minervas moldeadas.

La gran mayoría de estas fracturas son estables y pueden ser tratadas mediante métodos conservadores, nosotros utilizamos Minervas moldeadas occipitocervicales como primera opción terapéutica.

Sólo en aquellas fracturas con líneas de fractura a través de las masas laterales articulares del axis, y sobre todo si existe avulsión o conminución de estas masas laterales, planteamos de entrada un tratamiento quirúrgico mediante fijaciones occipitocervicales o interarticulares C1-C2 ( Fig. 7 ). Esta situación se presenta con mucha mayor frecuencia en las fracturas transversas altas del axis.

Un 5\% de fracturas del cuerpo del axis corresponde a fracturas-avulsiones de fragmentos anteroinferiores de $\mathrm{C} 2$. Su tratamiento puede efectuarse mediante métodos conservadores, aunque sólo se consiguen consolidaciones

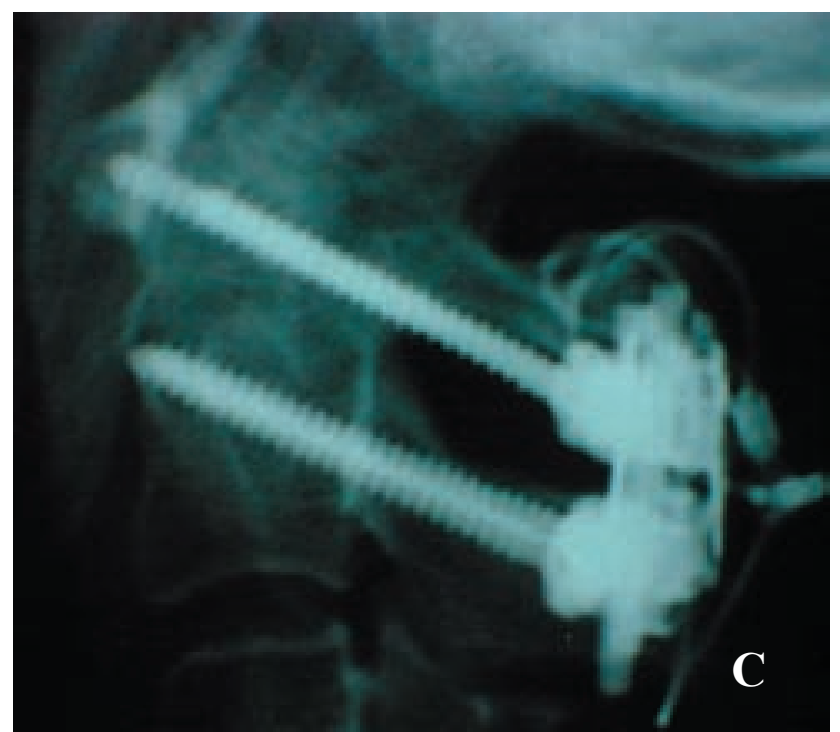

Figura 7. Fracturas transversas del cuerpo del axis. (7A) y (7B): Fractura tipo III de Benzel con desplazamiento anterior. Fijación transarticular C2-C1 posterior con tornillos, según técnica de Magerl y fijación interlaminar C1-C2 con cable laminar y hueso autólogo. (7C): Fractura Tipo III de Benzel con fijación $360^{\circ} \mathrm{C} 1-\mathrm{C} 2$.

sin correcta aposición de los fragmentos en la mayoría de los casos. Sin embargo esta situación no provoca dolor ni repercusión funcional posterior.

\section{Fracturas y luxaciones crónicas}

En algunas ocasiones las fracturas y luxaciones del complejo occipitoatloaxoideo pueden pasar desapercibidas al diagnóstico inicial, o bien la aplicación de tratamientos conservadores o el fracaso de tratamientos quirúrgicos iniciales pueden llevar a situaciones de inestabilidad, con peligro de aparición de lesión neurológica. No es infrecuente que determinadas lesiones traumáticas de este complejo se diagnostiquen semanas, meses o incluso años después del accidente. En ese caso la aparición de clínica neurológica tardía puede llevar al diagnóstico radiológico también tardío. Normalmente se tratará de graves lesiones muy inestables, que van a precisar tratamientos quirúrgicos para su estabilización.

Las más frecuentes son las fracturas crónicas de la base de la odontoides. En ocasiones, las fracturas agudas de la AO no se diagnostican inicialmente, pudiendo pasar desapercibidas durante mucho tiempo o bien fracasar técnicas de fijación indirectas iniciales, o incluso, aunque mucho menos frecuentemente, su atornillado anterior (Fig. 10). Las fracturas diagnosticadas meses o años después del accidente pueden manifestarse por sintomatología clínica de mielopatía cervical tardía y, en muchos casos, se obje- 
Neurocirugía

Traumatismos de la columna cervical alta: Clasificación tipológica, indicaciones terapéuticas y abordajes quirúrgicos ....

2006; 17: 391-419
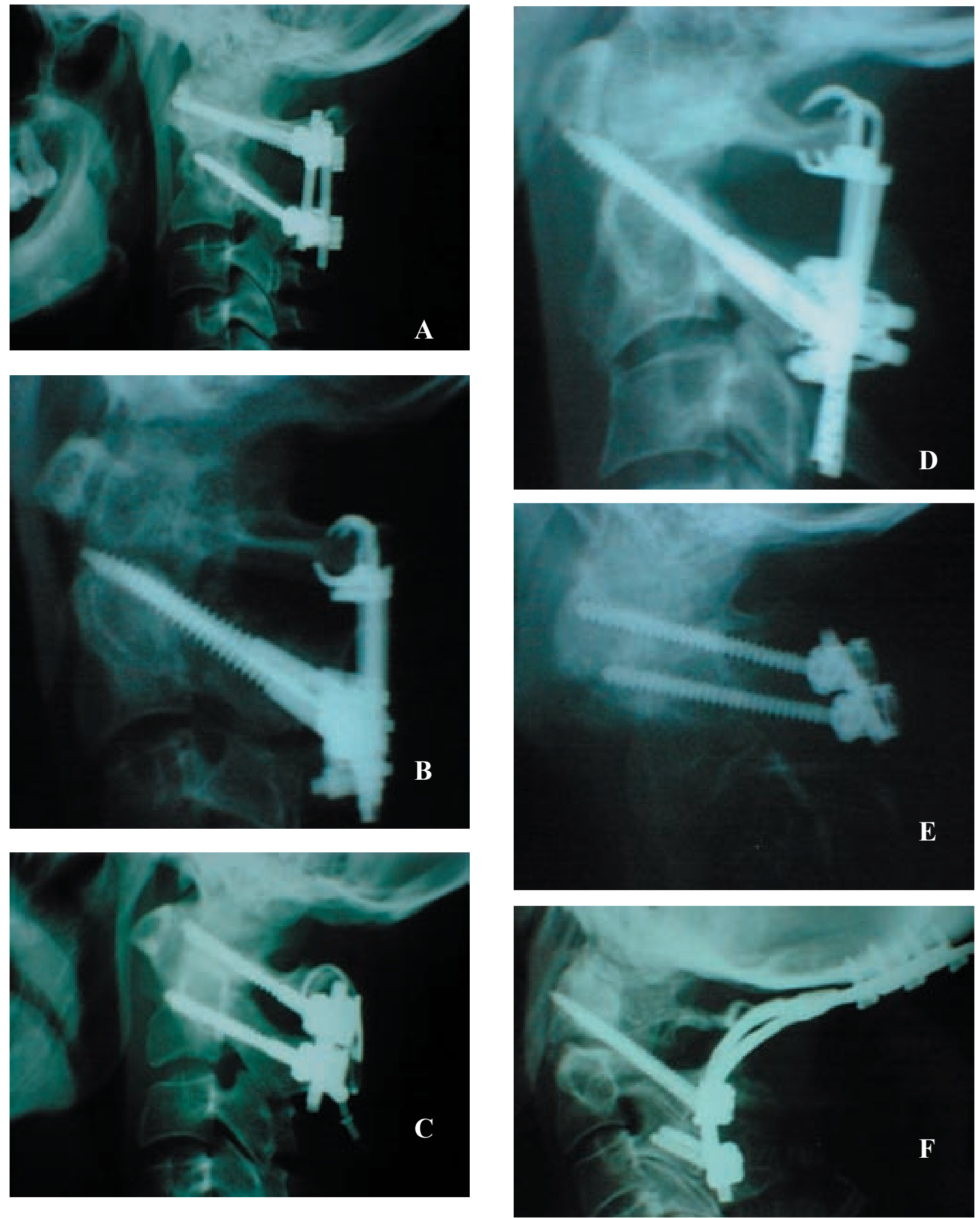

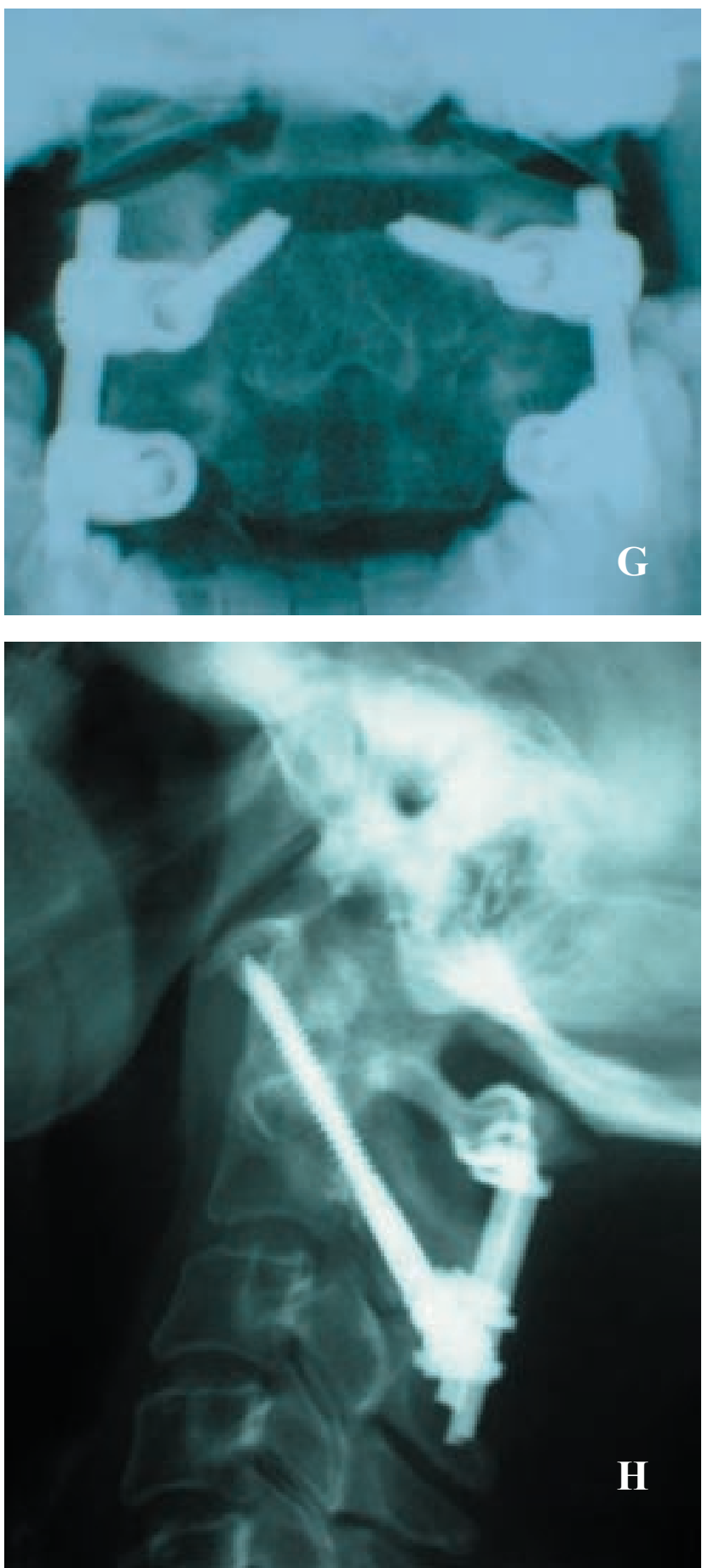

tiva en estudios de neuroimagen signos de compresión o señal medular en la RNM. Asimismo la gran mayoría de estas fracturas son marcadamente inestables objetivándose importantes desplazamientos de la odontoides en los estudios radiológicos funcionales. Para su tratamiento van a requerir siempre técnicas quirúrgicas de estabilización mediante fijaciones occipitocervicales en caso de asociar lesiones medulares, o bien fijaciones posteriores inter o transarticulares $\mathrm{C} 1-\mathrm{C} 2$ asociadas a veces a fijaciones interlaminares de este segmento ( Fig. 8 ) . No será infrecuente la necesidad de ampliar el espacio para la médula mediante resecciones del arco posterior de $\mathrm{C} 1$ o bien ampliando el foramen magnum. Un importante número de casos van a presentar una reacción pseudotumoral granulomatosa alrededor de la odontoides, reactiva a la hipermovilidad patológica que provocan estas fracturas crónicas (Fig. $8 \mathrm{H}$ ). Este tejido fibrogranulomatoso neoformado va a reducir considerablemente el espacio vertebral a este nivel y va a provocar compresiones y manifestaciones clínicas neurológicas. La aparición de este pseudotumor está en relación directa con el tiempo de evolución de la fractura crónica de la AO. Este tejido neoformado suele desaparecer después de la fijación quirúrgica de la fractura.

La ruptura del ligamento transverso del atlas, aislada o bien asociada a otras fracturas, también puede diagnosticarse tardíamente al constatar en estudios radiológicos luxaciones atloaxoideas progresivas. Su estabilización requerirá siempre técnicas de fijación posterior $\mathrm{C} 1-\mathrm{C} 2$. (Fig. 4)

Las fracturas de los pedículos del axis tratadas inicialmente con métodos conservadores, o también en casos no diagnosticados, pueden desarrollar una inestabilidad C2C3 que va a precisar una fijación posterior C2-C3. (Fig. 6 E-F-G).

\section{Fracturas y luxaciones asociadas atloaxoideas}

La existencia de fracturas y luxaciones combinadas de C1 y C2 es relativamente frecuente ${ }^{44,90}$. Para su producción son necesarias fuerzas patomecánicas muy importantes que normalmente implican la coexistencia de un mayor número de déficits neurológicos (12\%) que en el caso de fracturas aisladas del atlas $(0 \%)$ o del axis $(2 \%)$.

La combinación de fracturas de $\mathrm{C} 1$ y $\mathrm{C} 2$ se presenta en el $15 \%$ de las fracturas de la odontoides y en el $9 \%$ de las fracturas de los pedículos del axis.

Se han descrito numerosas posibilidades de combinaciones pero las más frecuentes son: fracturas de $\mathrm{C} 1 \mathrm{y}$ de la base de la apófisis odontoides (40\%), fracturas de C1 y fracturas del cuerpo del axis (28\%), fracturas de C1 y transversas de C2 (20\%), fracturas de C1 y de los pedículos de C2 (12\%) o fracturas de la apófisis odontoides asociada a ruptura del ligamento transverso del atlas.

La gran mayoría de estas fracturas son inestables.

En su planificación terapéutica cada fractura debe ser analizada individualmente y aplicar el tratamiento necesario en cada una de ellas. Así en las fracturas de C1 estables, asociadas a fracturas de la base de la odontoides se deberá proceder al atornillado anterior de esta última y colocar una Minerva moldeada occipitocervical (Fig. 9 A). En las frac- 

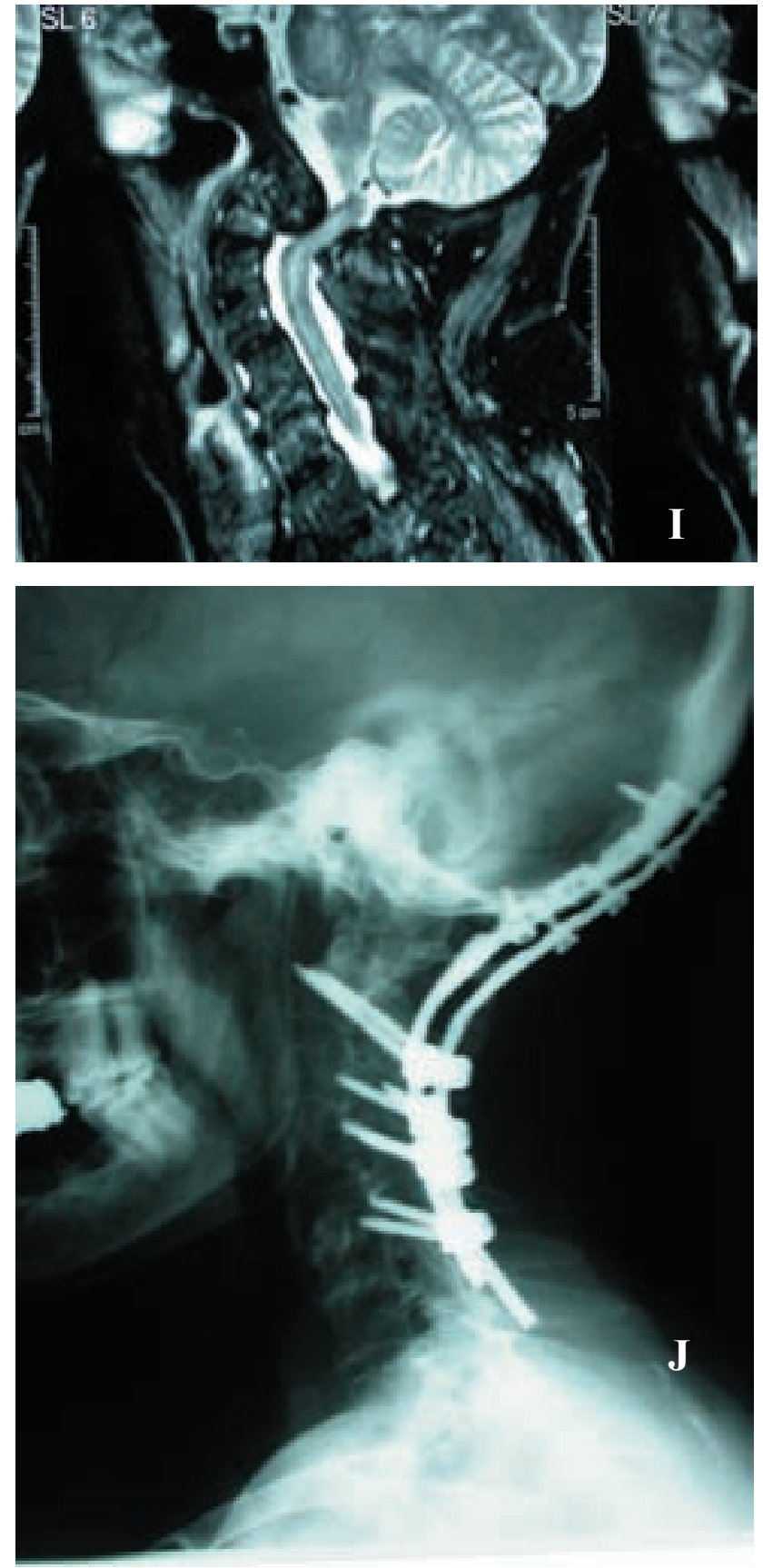

turas de los pedículos de C2 Tipo IIa asociada a fractura de la base de la odontoides se procederá al atornillado anterior de la odontoides y a la fijación posterior C2-C3 (Fig. 9 B ). En la asociación de una fractura de la odontoides y ruptura del ligamento transverso del atlas se procederá a la fijación posterior $\mathrm{C} 1-\mathrm{C} 2$ interarticular o transarticular asociada a una fijación interlaminar C1-C2 ( Fig. 9 C). En muchas otras combinaciones posibles un tratamiento conservador con halos o Minervas cervicales podría ser el tratamiento inicial adecuado.

Todos estos casos precisarán de exhaustivos controles

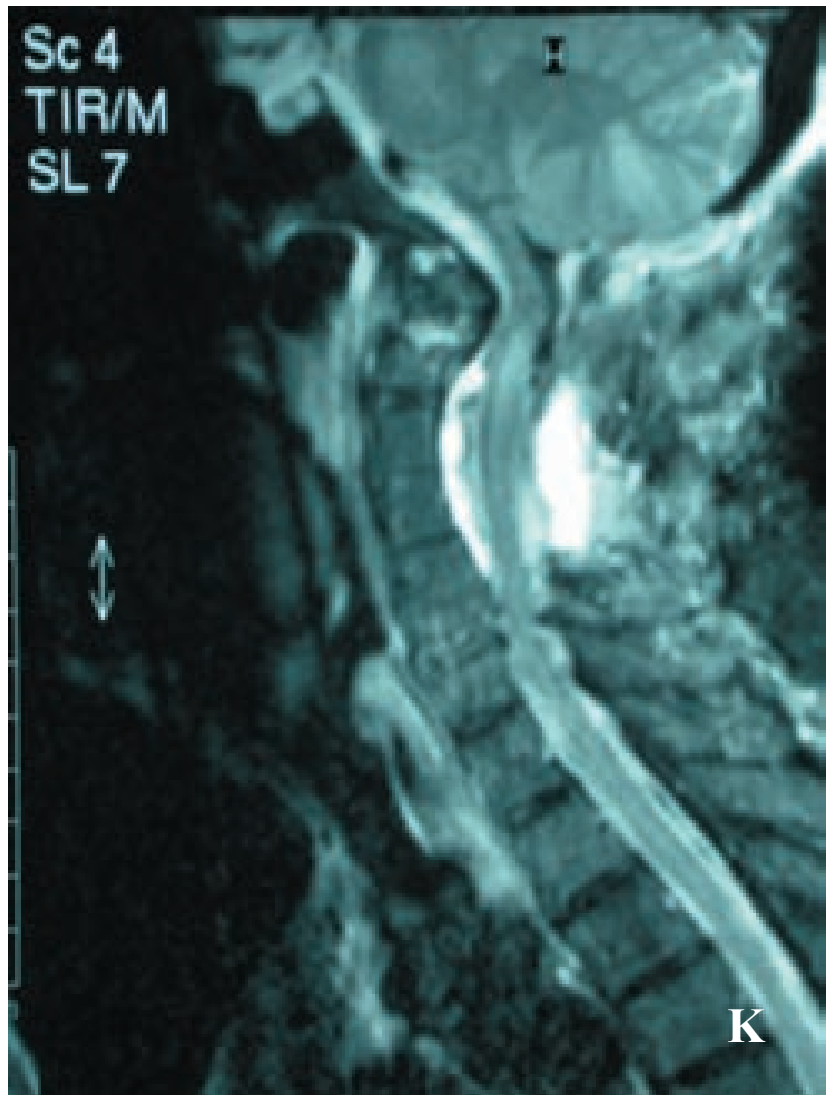

Figura 8. Fracturas crónicas de la base de la odontoides. (8A): Fijación interarticular C1-C2 según técnica de GoelHarms. (8B) y (8D): Fijación posterior C1-C2 según técnica de Olerud. (8C): Fijación Goel-Harms asociada a fijación interlaminar C1-C2 con malla de titanio, cable laminar y hueso autólogo. (8E): Fijación unilateral Goel-Harms en paciente de 95 años. (8F): Fijación occipitocervical. (8G$H)$ :Fractura crónica odontoides, $R N M$ preoperatoria, $R X$ postquirúrgica. (8I-J-K):Fractura-ptosis crónica de la base de la odontoides, RNM pre y postquirúrgica y Rx con fijación occipitocervical.

radiológicos evolutivos y funcionales para, en su caso, modificar la decisión terapéutica inicial.

La gran mayoría de las lesiones traumáticas del complejo $\mathrm{C} 0-\mathrm{C} 1-\mathrm{C} 2$ tienen una enorme potencialidad lesiva evolutiva; por ello, estas lesiones, incluso las diagnosticadas y tratadas precozmente, van a requerir controles evolutivos clínicos y radiológicos por largos períodos de tiempo.

Hoy en día, los medios de imagen permiten tipificar correctamente cada una de las posibles luxaciones y fracturas del complejo $\mathrm{C} 0-\mathrm{C} 1-\mathrm{C} 2$; ello nos permite proponer en cada caso el método de tratamiento más correcto con el fin de conseguir lo más rápido posible la liberación de estructuras neurales, si existen, fijar la fractura o luxación con la mayor reducción posible y en todo caso evitar una posible 

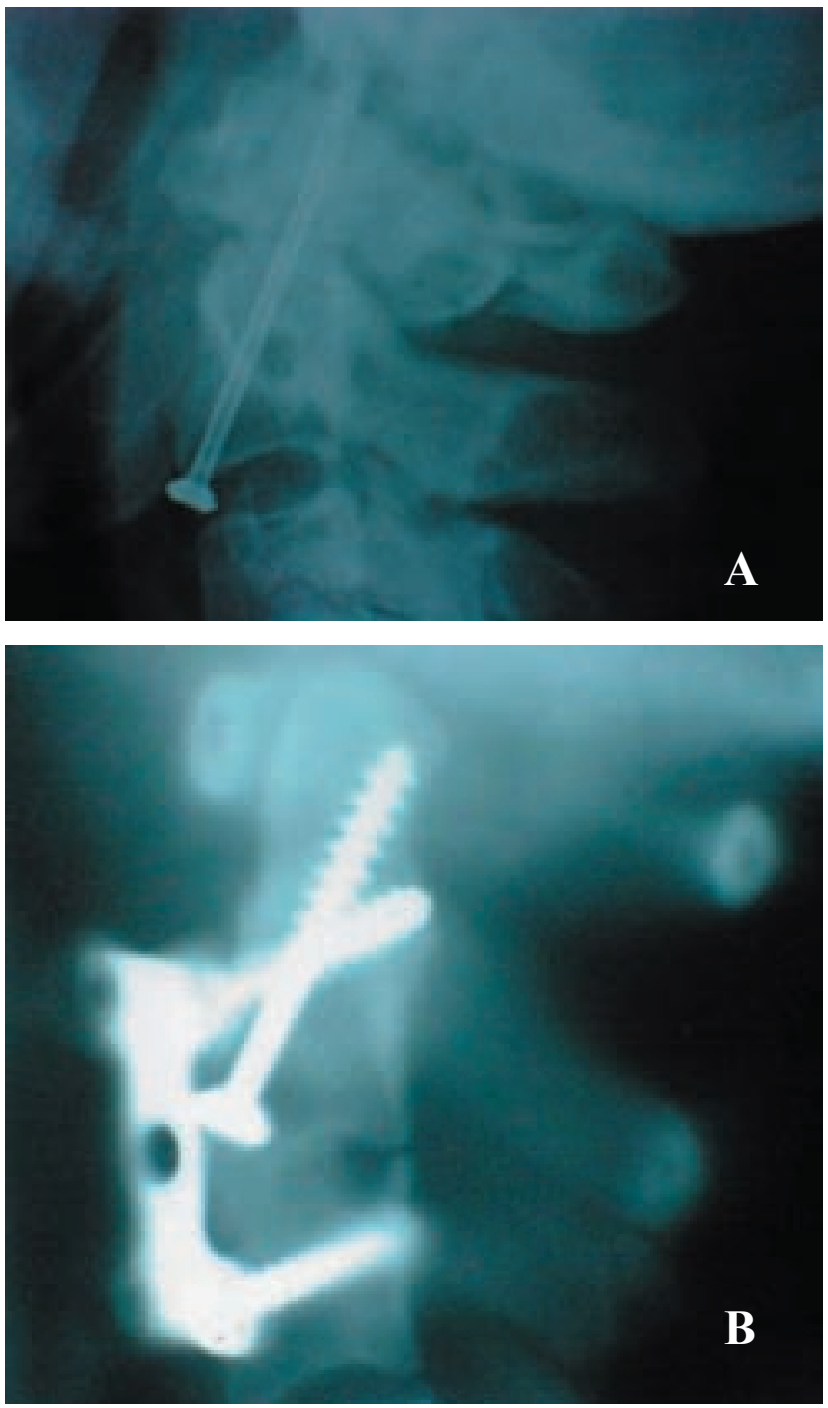

Figura 9. Fracturas combinadas atloaxoideas. (9A): Fractura de la base de la odontoides y fractura del arco posterior del atlas. (9B): Fractura de la base de la odontoides y fractura de los pedículos del axis.

evolutividad biomecánica o neurológica de estas lesiones.

Las técnicas de instrumentación sobre este segmento cervical son múltiples y eficaces. Las técnicas conservadoras en ocasiones, cuando están indicadas, también pueden resultar útiles. La mayoría de las técnicas quirúrgicas son muy demandantes y requieren un correcto aprendizaje y minuciosidad en su aplicación por el mismo riesgo, algunas veces vital, que conlleva su ejecución. Es imprescindible el efectuar estudios de neuroimagen previos que permitan valorar tanto las posibles desviaciones de la anatomía provocadas por los accidentes como posibles malformaciones previas sobre todo del trayecto de las arterias vertebrales. Por ello la propuesta terapéutica ofrecida a nuestros pacientes deberá tener en cuenta, entre otros factores, la anatomía
2006; 17: 391-419
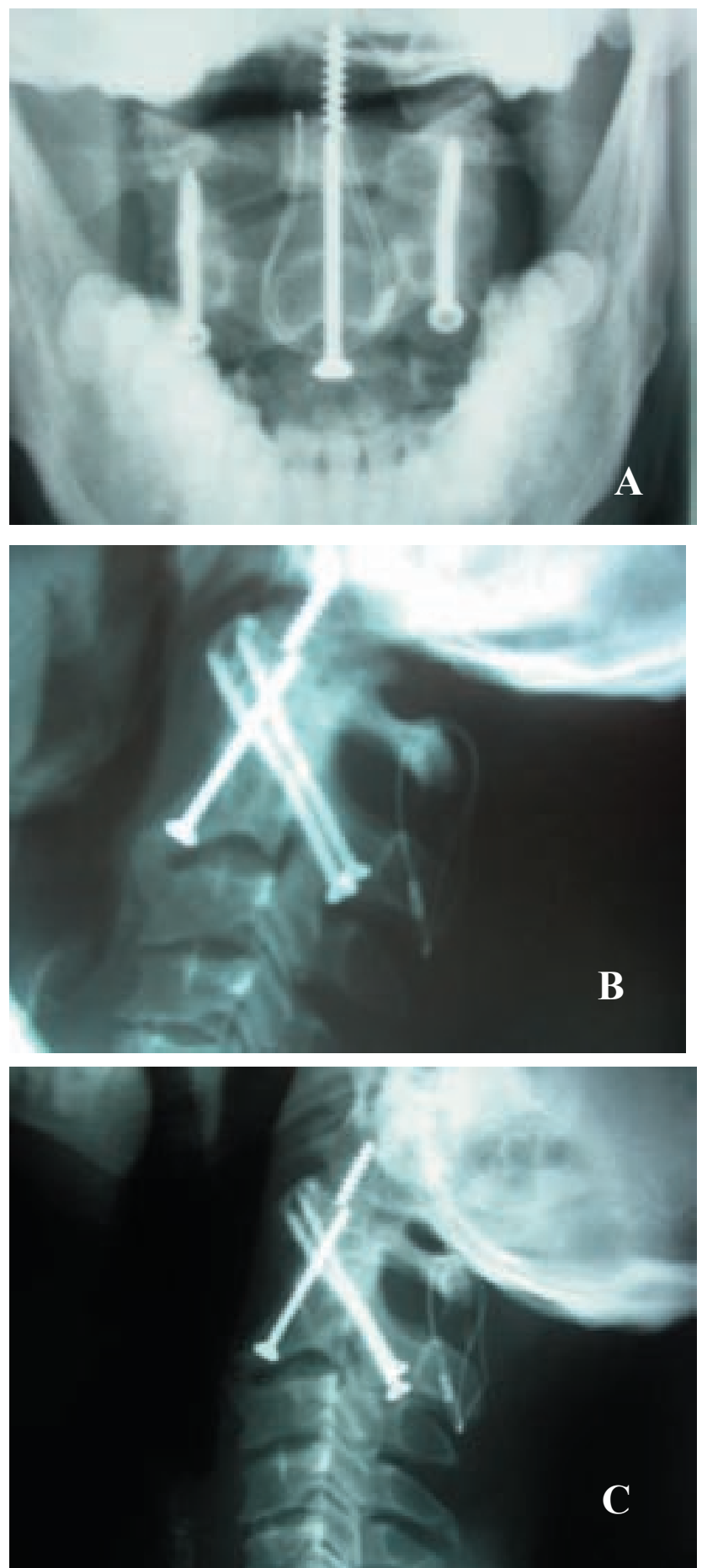

Figura10. Pseudoartrosis fractura odontoides. (fracaso atornillado). (10A-B-C): Falta de unión de fractura aguda de odontoides tras su atornillado inicial. Fijación transarticular C1-C2 e interlaminar C1-C2, ruptura tornillos transarticulares.

patológica de cada lesión, su posible evolutividad, la experiencia previa y la habilidad de los equipos tratantes. 


\section{GUÍA TERAPÉUTICA}

\begin{tabular}{|c|c|c|}
\hline Lesión & $1^{a}$ Opción terapeútica & $\begin{array}{c}2^{a} \text { Opción terapéutica } \\
\text { (fracaso o imposibilidad de la } 1^{a} \text { opción) }\end{array}$ \\
\hline $\begin{array}{l}\text { Luxación C0-C1 Tipo I } \\
\text { Luxación C0-C1 Tipo II } \\
\text { Luxación C0-C1 Tipo III }\end{array}$ & $\begin{array}{l}\text { Fijación occipitocervical } \\
\text { Artrodesis transarticular C1- Co }\end{array}$ & Halo craneotorácico \\
\hline Fractura cóndilo C0 Tipo I & Minerva moldeada occipitocervical & Fijación occipitocervical \\
\hline Fractura cóndilo C0 Tipo II & Minerva moldeada occipitocervical & \\
\hline Fractura cóndilo Co Tipo III & Minerva moldeada occipitocervical & Fijación occipitocervical \\
\hline Luxación rotatoria C1- C2 Tipo I & Ortesis Philadelphia & \\
\hline Luxación rotatoria C1- C2 Tipo II & Ortesis Philadelphia & $\begin{array}{l}\text { Tracción cervical } \\
\text { SOMI } \\
\text { Halo craneotorácico } \\
\text { Fijación interlaminar C1-C2 }\end{array}$ \\
\hline Luxación rotatoria C1- C2 Tipo III & $\begin{array}{l}\text { (Tracción cervical) } \\
\text { Fijación interlaminar C1-C2 } \\
\text { Fijación interarticular C1-C2 } \\
\text { Fijación C1- C2 360 }\end{array}$ & $\begin{array}{l}\text { Fijación interlaminar C1-C2 } \\
\text { Halo craneotorácico } \\
\text { Minerva moldeada cervical }\end{array}$ \\
\hline Luxación rotatoria C1- C2 Tipo IV & $\begin{array}{l}\text { (Tracción cervical) } \\
\text { Fijación interarticular C1- C2 } \\
\text { Artrodesis transarticular C1- C2 } \\
\text { Fijación C1- C2 } 360^{\circ}\end{array}$ & Halo craneotorácico \\
\hline Ruptura lig. transv. C1 Tipo I & $\begin{array}{l}\text { Fijación C1- C2 } 360^{\circ} \\
\text { Fijación interarticular C1- C2 } \\
\text { Artrodesis transarticular C1- C2 }\end{array}$ & \\
\hline Ruptura lig. transv. C1 Tipo II & $\begin{array}{l}\text { Minerva moldeada cervical } \\
\text { Halo craneotorácico }\end{array}$ & $\begin{array}{l}\text { Fijación interarticular C1-C2 } \\
\text { Artrodesis transarticular C1-C2 } \\
\text { Fijación occipitocervical }\end{array}$ \\
\hline Fractura del atlas Tipo a & Ortesis Philadelphia & \\
\hline Fractura del atlas Tipo b & Ortesis Philadelphia & \\
\hline Fractura del atlas Tipo c & Minerva moldeada cervical & \\
\hline Fractura del atlas Tipo d & $\begin{array}{l}\text { Minerva moldeada cervical } \\
\text { Halo craneotorácico }\end{array}$ & Fijación occipitocervical \\
\hline Fractura del atlas Tipo e & $\begin{array}{l}\text { Fijación occipitocervical } \\
\text { Halo craneotorácico } \\
\text { (tracción cervical) }\end{array}$ & $\begin{array}{l}\text { Fijación interarticular C1-C2 } \\
\text { Artrodesis transarticular C1-C2 }\end{array}$ \\
\hline Fractura del atlas Tipo $\mathrm{f}$ & Minerva moldeada cervical & \\
\hline Fractura ápex odontoides & Ortesis Philadelphia & \\
\hline Fractura base odontoides & Atornillado anterior de $\mathrm{C} 2$ & $\begin{array}{l}\text { Fijación interarticular C1-C2 } \\
\text { Artrodesis transarticular C1-C2 } \\
\text { Fijación C1-C2 } 360^{\circ} \\
\text { Halo craneotorácico }\end{array}$ \\
\hline
\end{tabular}




\begin{tabular}{|c|c|c|}
\hline Fractura pedículo C2 Tipo I & Minerva moldeada cervical & \\
\hline Fractura pedículo C2 Tipo II & $\begin{array}{l}\text { Minerva moldeada occipitocervical } \\
\text { SOMI }\end{array}$ & $\begin{array}{l}\text { Fijación posterior C2-C3 } \\
\text { Artrodesis anterior } \mathrm{C2}-\mathrm{C3}\end{array}$ \\
\hline Fractura pedículo C2 Tipo IIa & $\begin{array}{l}\text { Fijación posterior C2- C3 } \\
\text { Artrodesis anterior C2- C3 }\end{array}$ & Halo craneotorácico \\
\hline Fractura cuerpo C2 Tipo I & Minerva moldeada cervical & Fijación occipitocervical \\
\hline Fractura cuerpo C2 Tipo II & Minerva moldeada cervical & Fijación occipitocervical \\
\hline Fractura cuerpo C2 Tipo III & $\begin{array}{l}\text { Minerva moldeada occipitocervical } \\
\text { Halo } \\
\text { SOMI }\end{array}$ & $\begin{array}{l}\text { Fijación interarticular C1-C2 } \\
\text { Artrodesis transarticular C1-C2 } \\
\text { Fijación C1-C2 } 360^{\circ} \\
\text { Fijación occipitocervical }\end{array}$ \\
\hline Fractura crónica odontoides & $\begin{array}{l}\text { Fijación interarticular C1- C2 } \\
\text { Artrodesis transarticular C1- C2 } \\
\text { Fijación C1- C2 } 360^{\circ} \\
\text { Fijación occipitocervical }\end{array}$ & Resección anterior de la odontoides \\
\hline $\begin{array}{l}\text { Ruptura crónica ligamento } \\
\text { transverso del atlas }\end{array}$ & $\begin{array}{l}\text { Fijación interarticular C1- C2 } \\
\text { Artrodesis transarticular C1- C2 } \\
\text { Fijación C1- C2 } 360^{\circ} \\
\text { Fijación occipitocervical }\end{array}$ & \\
\hline Fractura crónica pedículos C2 & $\begin{array}{l}\text { Fijación posterior C2- C3 } \\
\text { Artrodesis anterior C2- C3 }\end{array}$ & Fijación occipitocervical \\
\hline Fractura crónica cuerpo C2 Tipo III & $\begin{array}{l}\text { Fijación occipitocervical } \\
\text { Fijación interarticular C1- C2 } \\
\text { Artrodesis transarticular C1- C2 } \\
\text { Fijación C1- C2 } 360^{\circ}\end{array}$ & \\
\hline
\end{tabular}

\section{Bibliografía}

1. Adams, V.I.: Neck injuries: II. Atlantoaxial dislocation a pathologic study of 14 traffic fatalities. J Forensic Sci 1992; 37: 565-573.

2. Althoff, B.O.: Fracture of the Odontoid Process. An experimental and clinical study. Acta Orthop Scand 1979; 177 [Suppl]:1-95.

3. Anderson, L.D., D'Alonzo, R.T.: Fractures of the Odontoid Process of the axis. J Bone Joint Surg (Am) 1974; 56: 1663-1674.

4. Anderson, P.A., Montesano, P.X.: Morphology and treatment of occipital condyle fractures. Spine 1988; 13:731736.

5. Apfelbaum, R.I., Lonser, R.R., Veres, R., Casey, A.: Direct anterior screw fixation for recent and remote odontoid fractures. J Neurosurg 2000; 93 [Suppl 2]: 227-236.

6. Apuzzo, M.J., Heiden, J.S., Weis, M.H., Ackerson, T.T., Harvey, J.P., Kurze, T.: Acute fractures of the odontoid process. An analysis of 45 cases. J Neurosurg 1978; 48: 85-91.

7. Arand, M., Lemke, M., Kinzl., Hartwig, E.: Incidence of complications of the screw osteosynthesis of odontoid proces fractures. Zentralbl Chir 2001; 126: 610-615,.

8. Bachs,A., Barraquer-Bordas, L., Barraquer-Ferré.L., Canadell, J.M., Modolell, A.: Delayed myelopathy following atlanto-axial dislocation by separated odontoid proces. Brain 1958; 78: 537-553.

9. Barbour, J.R.: Screw fixation and fractures of the odontoid proces. S Aust Chir 1971; 5: 20-24.

10. Baum, J.A., Hanley, ENJr., Pullekines, J.: Comparison of halo complications in adults and children. Spine 1989; 14: 251-252.

11. Bell, C.: Surgical observations. Middlesex Hosp J. 4: $469,1817$.

12. Benzel, E.C., Hadden, T.A., Saulsbery, C.M.: A comparison of the Minerva and Halo jackets for stabilization of the cervical spine. J Neurosurg. 1989; 70: 411-414.

13. Benzel, E.C., Hart,B.L., Ball, P.A., Baldwin, N.G., Orrison, W.W., Espinosa, M.C.: Fractures of the C2 vertebral body. J Neurosurg 1994; 81: 206-212.

14. Berlemann, U., Schwarzenbach, O.: Dens fractures in the elderly. Results of anterior screw fixation in 19 elderly 
patients. Acta Orthop Scand 1997; 68: 319-324.

15. Bilbao, G., Martín-Ferrer, S., Garibi, J.: Chronic atlanto-axial dislocation. Pediatric Neurosurgery (en prensa).

16. Böhler, J.: Anterior stabilization for acute fractures and non-union of the dens. J Bone Joint Surg (Am) 1982; 64: 827.

17. Borm, W., Kast, E., Richter, H.P., Mohr, K.: Anterior screw fixation in type II odontoid fractures: is there a difference in outcome betwen age groups? Neurosurgery 52: 10891094.

18. Borne, G.M., Bedou, G.L., Pinaudeau, M.: Treatment of pedicular fractures of the axis: A Clinical study and screw fixation thecnique. J Neurosurg 1984; 60: 88-93.

19. Bucholz, R.D., Cheung, K.C.: Halo vest versus spinal fusion for cervical injury: evidence from an outcome study. J Neurosurg 1989; 70: 884-892.

20. Chang, K.W., Liu, Y.W., Cheng, P.G., Chang, L., Suen, K.L., Chung, W.L.: One Herbert double-threaded compression screw fixation of displaced type II odontoid fractures. J Spinal Disord 1994; 7: 62-69.

21. Clark, C.R., White, A.A III.: Fractures of the dens. A multicenter study. J Bone Joint Surg (Am) 1985; 67A: 13401348 .

22. Crockard, M.A., Heilman, A.E., Stevens, J.M.: Progressive myelopathy secondary to odontoid fractures: clinical, radiological, and surgery features. J Neurosurg 1993; 78: 579586.

23. Cybulski, G.R., Stone, J.L., Crowell, R.M. et al. : Use of Halifax interlaminar clamps for posterior C1-C2 arthrodesis. Neurosurgery 1988; 22:429-431.

24. Dickman, C.A., Greene, K.A., Sonntag, V.K.H.: Taumatic injuries of the craneovertebral junction. En Surgery of the Craniovertebral junction. Dickman, C.A., Spetzler, R.F., Sonntag, V.K.H. Ed. Thieme 1998; pp 175-196.

25. Dickman, C.A., Greene, K.A., Sonntag, V.K.H.: Injuries involving the transverse atlantal ligament: classification and treatment guidelines based upon experience with 39 injuries. Neurosurgery 1996: 38: 44-50.

26. Dublin, A.B., Marks, W.M., Weinstock, D., Newton, T.H.: traumatic dislocation of the atlanto-occipital articulations (AOA) with short-term survival: With a radiographic method of measuring the AOA. J Neurosurg 1980; 52: 541546.

27. Effendi, B., Roy, D., Cornish, B., Dussault, R.G., Laurin, C.A.: Fractures of the ring of the axis: A classification based on the analysis of 131 cases. J Bone Joint Surg Br 1981; 63B: 319-327.

28. Eleraky, M.A., Theodore, N., Adams, M., Rekate, H.L., Sonntag, V.K.M.: Pediatric cervical spine injuries: Report of 102 cases and review of the literature. J Neurosurg 2000; 92 [Suppl1]: 12-17.

29. Ersmark, H., Dalen, N., Kalen, R.: Cervical spine injuries: a follow-up of 332 patients. Paraplejia 1990; 28: 25-40.
30. Eysel, P., Roosen, K.: Ventral or dorsal spondylodesis in dens basal fracture: a new classification for choice of surgical approach Zentralbl Neurochir 1993; 54: 159-165.

31. Fielding, J.W., Hawkins, R.J.: Atlanto-axial rotary fixation: Fixed rotatory subluxation of the atlanto-axial joint. J Bone Joint Surg Am 1977; 59A:3 7-44.

32. Florensa, R., Noboa, R., Muñoz, J., Colet, S., Cladellas, J.M., Rodríguez, Mª.A., Ley,A.: Resultados de la fijación transarticular $\mathrm{C} 1-\mathrm{C} 2$ en una serie de 20 pacientes. Neurocirugía 2002; 13: 429-436

33. Francis, W.R., Fielding, J.W., Hawkins, R.J., Pepin, J., Hensinger, R.: Traumatic spondylolistesis of the axis. J Bone Joint Surg Br 1981; 63B: 313-318.

34. Gallie, W.: Fractures and dislocations of the cervical spine. Am J Surg1939; 46: 495-499.

35. Gaskill, S.J., Marlin, A.E.: Custom fitted thermoplastic Minerva jackets in the treatment of cervical spine instability in preschool age children. Pediatr Neurosurg 1990; 16:35-39.

36. Geisler, F.H., Cheng, C., Poka, A., Brumback, R.J.: Anterior screw fixation of posterioly displaced type II odontoid fractures. Neurosurgery 1989: 25: 30-38.

37. Godard, J., Hadji, M., Raul, J.S.: Odontoid fractures in the child with neurological injury. Direct anterior osteosynthesis with a cortico-spongious screw and literature review. Childs Nerv Syst 1997; 13: 105-107.

38. Goel, A., Desai, K.I., Muzumdar, D.P.: Atlantoaxial fixation using plate and screw method: a report of 160 treated patients. Neurosurgery 51: 1351-1357,2002.

39. Goel, A., Laheri, V.: Plate and screw fixation for atlanto-axial subluxation. Acta Neurosurg (Wien) 1994: 129: 47-53.

40. Gonzalez, L.F., Crawford, N.R., Chamberlain, R.H., Perez Garza, L.E., Preull, M.C., Sonntag, V.K.H.: Craniovertebral junction fixation with transarticular screws: biomechanical analysis of a novell technique. J Neurosurg (Spine) 2003; 98: 202-209.

41. González, L.F., Sonntag, V.K.H., Dickman, C.A., et al.: Technique for fixating the atlantooccipital complex with a transarticular screw. Spine 2002; 27: 219-220.

42. Grob, D.: Transarticular screw fixation for atlantooccipital dislocation. Spine 2001; 26: 703-707.

43. Guyotat, J., Perrin, G., Pelissou, I., Daher, T., Bachour, E.: Utilization du matériel de Cotrel Dubousset dans les instabilités C1-C2. Neurochirurgie 1987; 33: 236-238.

44. Hadley, M.N.: Management of combination Fractures of the atlas and axis in adults. Neurosurgery 2002; 50 [Suppl]: 140-147

45. Hadley, M.N., Dickman, C.A., Browner, C.M., Sonntag, V.K.H.: Acute traumatic atlas fractures: Management and long term outcome. Neurosurgery 1988; 23: 31-35.

46. Hadley, M.N.: Isolated fractures of the axis in adults. Neurosurgery 2002; 50: 125-139

47. Hanigan, W.C., Powell, F.C., Elwood, P.W., Hender- 
son, J.P.: Odontoid fractures in ederly patients. J Neurosurg 1993; 78: 32-35.

48. Hanley, EN Jr., Harvell, J.C.Jr.: Immediate postoperative stability of the atlantoaxial articulation: a biomechanical study comparing simple midline wiring, and the Gallie and Brooks procedures. J Spinal Disord 1992; 5:306-310.

49. Harms, J., Melcher, R.P.: Posterior C1-C2 fusion with polyaxial screw and rod fixation. Spine 2001; 26:2467-2471.

50. Harris, J.H. Jr., Carson, G.C., Wagner, L.K., Kerr, N.: Radiologic diagnosis of traumatic occipitovertebral dissociation: Part 2 - Comparison of three methods of detecting occipitovertebral relationships on lateral radiographs of supine subjects. Am J Radiol 1994; 162: 887-892.

51. Hashizume, H., Kawakami, M., Kawai, M., Tamaki, T.: A clinical case of endoscopically assisted anterior screw fixation for type II odontoid fracture. Spine 2003; 28: E102105,2003

52. Horgan, M.A., Hsu, F.P., Frank, E.H.: A novel endoscopic approach to anterior odontoid screw fixation technical note. Minim Invasive Neurosurg 1999; 42: 142-145.

53 Hott, J.S., Henn, J.S., Sonntag, V.K.H.: A new tablefixed retractor for anterior odontoid screw fixation. Technical note. J Neurosurg (Spine) 2003; 98: 294-296.

54. Jahna, H.: Therapy and therapeutic results in 90 odontoid proces fractures and dislocation-fracture. Hefte Unfallheilkd 1971; 108: 72-76.

55. Jeanneret, B., Magerl, F.: Primary posterior fusion C1/ C2 in odontoid fractures: indications, technique, and results of transarticular screw fixation. J Spinal Disord 1992; 5: 464-475.

56. Jefferson, G.: Fractures of the atlas vertebra: Report of four cases and a review of those previously reported. Br J Surg 1920; 7: 407-422.

57. Jenkins, J.D., Coric, D., Branch, C.L.: A clinical comparison of one and two screw odontoid fixation. J Neurosurg 1998; 89: 366-370.

58. Julien, T.D., Frankel, B., Trynelis, V.C., Ryken, T.C.: Evidence-based analysis of odontoid fracture management. Neurosurg Focus 2000; 8: Article 1.

59. Junge, A., Gotzen, L., Wiemers, F.: Surgical management of a dens fracture in a 3-year-old child. Clinical case report and discussion with reference to the literature. Unfallchirurg 1994; 97: 410-412.

60. Kazan, S., Tuncer, R., Sindel, M.: Percutaneous anterior odontoid screw fixation technique. Acta Neurochir (Wien) 1999; 141: 521-524.

61. Khodadadyan-Klostermann, C., Kandziora, F., Schnake, K.J. Harms, J.: Transoral atlanto-axial plate fixation in the treatment of a malunited dens fracture and secondary atlanto-axial instability. Chirurg 2001; 72: 1298-302.

62. Lee, C., Woodring, J.H., Goldstein, S.J., Daniel, T.L., Young, A.B., Tibbs, P.A.: Evaluation of traumatic atlantooccipital dislocations. AJNR Am J Neuroradiol 19878: 19-26.

63. Lesoin, F., Autricque, A., Villette, L., Franz, K., Jomin,
J.: Arthrodèse atloido-axoidienne par abord antérieur intermaxillo-hyoidien rétropharyngé. Neurochirurgie1987; 33: 239-243.

64. Levine, A.M., Edwards, C.C.: The management of traumatic spondylolistesis of the axis. J Bone Joint Surg Am 1985; 67A: 217-226.

65. Magerl, F., Seeman, P.S.: Stable posterior fusion of the atlas and axis by transarticular screw fixation. In Kehr, P., Weidner, A. eds. Cervical Spine I. New York, Wien:Springer 1986; pp 322-327.

66. Martín-Ferrer, S., Rimbau, J., Feliu, R., Pont, J., Teruel, J.: Tratamiento de las fracturas de la apófisis odontoides. A propósito de 21 casos. En Guillén García, P. Columna vertebral. Ed. Mapfre. Madrid. 1996: pp. 151-181.

67. Martín-Ferrer, S., Rimbau, J., Feliu, R.: Atornillado anterior en las fracturas agudas de la odontoides. Neurocirugía 1996; 7: 89-99.

68. Martín-Ferrer, S., Rimbau, J., Joly, Mª.C., Teruel, J., Pont, J.: Atornillado transarticular posterior atloaxoideo en la inestabilidad del complejo C0-C1-C2. Neurocirugía 2000; 11: 43-49

69. Martín-Ferrer, S., Rimbau, J., Joly, MC., Teruel, J., Pont, J.: Fracturas de la apófisis odontoides: Revisión de nuestra casuística, implicaciones terapeúticas y nueva clasificación. Neurocirugía 1999; 10: 426-438.

70. Martín-Ferrer, S.: Manejo actual de las fracturas de la apófisis odontoides. En Guillén García, P. Columna cervical y hombro. Ed. Mapfre. Madrid. 2000: pp 99-134.

71. Martín-Ferrer, S.: Odontoid fractures. J Neurosurg (Spine)2001; 95: 158-159.

72. Mestdagh, H., Vigier, Ph., Berger, M., Urvoy, Ph.: Résultats de l'arthrodèse atloido-axoidienne avec cerclage postérieur pour fractures de l'odontoide. A propós de cinquante-neuf cases. Ann Chir 1988; 42: 492-500.

73. Mixter, S.J., Osgood, R.B.: Traumatic lesions of the atlas and axis. Ann Surg 1910; 51: 193-207.

74. Nakanishi, T.: Internal fixation of odontoid fracture. Orthopaedic and Traumatic Surgery 1980; 23: 399-406.

75. Osgood, R.B., Lund, C.C.: Fractures of the odontoid proces. New Engl J Med 1928; 198: 61-71.

76. Pepin, J.W., Hawkins, R.J.: Traumatic spondylolistesis of the axis: Hangman's fracture. Clin Orthop 1981; 133138 .

77. Pilcher, L.S.: Subluxation of the atlas. Ann Surg 1910; 51: 208-211.

78. Polin, R.S., Szabo, T., Bogaev, C.V., Replogle, R.E., Jane, J.A.: Nonoperative management of types II and III odontoid fractures. The Philadelphia collar versus the halo vest. Neurosurgery 1996; 38: 450-456.

79. Powers, B., Miller, M.D., Kramer, R.S., Martínez, S., Gehweiler, J.A. Jr.: Traumatic anterior atlanto-occipital dislocation. Neurosurgery 1979: 4: 12-17.

80. Roy-Camille, R., Saillant, G., Lapresle, P., Leonard, 
P.: Recent fractures of the odontoid. prognostic factors. Presse Med 1983; 12: 2233-2236.

81. Schaffler, M.B., Alson, M.D., Heller,J.G., Garfin, S.R.: Morphology of the dens. A Quantitative study. Spine 1992; 17 : 738-743.

82. Schatzker, J., Rorabeck, C.H., Waddell, J.P.: Nonunions of the odontoid process.An experimental investigation. Clin Orthop 1975; 108: 127-137.

83. Schweigel, J.F.: Halo-thoracic brace management of odontoid fractures. Spine 1979; 4: 192-194.

84. Spence, K.F. Jr., Decker, M.S., Sell, K.W.: Bursting atlantal fracture associated with rupture of the transverse ligament. J Bone Joint Surg Am 1970; 52: 543-549.

85. Traynelis, V.C., Marano, G.D., Dunker, R.O., Kaufman, H.H.: Taumatic atlanto-occipital dislocation: Case report. J Neurosurg 1986; 65: 863-870.

86. Urculo, E., Arrazola, M., Arrazola, M. Jr., Riu, I., Moyua, A.: Delayed glossopharyngeal and vagus nerve paralysis following occipital condyle fracture: Case report. J Neurosurg 1996; 84: 522-525.

87. Wackenheim, A.: Roentgen Diagnosis of the Craniovertebral Region. New York, NY: Ed. Springer-Verlag 1974;

\section{Comentario al trabajo Traumatismos de la columna cer- vical alta: Clasificación tipológica, indicaciones terapéu- ticas y abordajes quirúrgicos (a propósito de 286 casos) de S. Martín Ferrer}

En el tratamiento de las fracturas cervicales existen pocos estudios Clase I o II, siendo la mayoría de los trabajos series retrospectivas o experiencia de autores. Una de las pocas evidencias basadas en un estudio Clase II es el de Lennarson et $\mathrm{al}^{2}$. Este autor demuestra una mejor evolución en los pacientes con fracturas de odontoides Tipo II, mayores de 50 años, intervenidos quirúrgicamente frente a aquéllos que sólo fueron tratados con inmovilización externa. Hoy día, la mayoría de los autores están de acuerdo con esta afirmación. Tampoco existen estándares o protocolos que demuestren una preferencia por la vía posterior o por la vía anterior, pudiendo utilizarse cualquiera de ellas.

El autor muestra su predilección por el tratamiento de estas fracturas mediante la técnica de fijación anterior de odontoides con un único tornillo (74 casos de un total de 78 pacientes). Dicha técnica muestra aceptables resultados de fusión en manos experimentadas (90\% en una revisión sistemática y $94 \%$ el autor), aunque se describe una cifra elevada de complicaciones durante la curva de aprendizaje ( $19 \%$ en este trabajo $)^{1,3}$. Otra contraindicación relativa de esta técnica es la presencia de rotura del liga- pp 660 .

88. Wasserberg, J., Bartett, R.J.V.: Occipital condyle fractures diagnosed by high-definition $\mathrm{CT}$ and coronal reconstructions. Neuroradiology 1995; 37: 370-373.

89. Wholey, M.H., Bruwer, A.J., Baker, H.L.: The lateral roentgenograms of the neck (with comments on the atlantoodontoid-basion relatioship). Radiology 1958; 71:350-356.

90. Yoon, D.H., Yang, K.H., Kim, K.N., Oh, S.H.: Posterior atlantoaxial dislocation without fracture. J Neurosurg (Spine) 2003; 98: 73-76.

91. Ziai, W.C., Hurlbert, R.J.: A six year review of odontoid fractures: the emerging role of surgical intervention. Can J Neurol Sci 2000; 27: 297-301.

Martín-Ferrer, S.: Traumatismos de la columna cervical alta: Clasificación tipológica, indicaciones terapéuticas y abordajes quirúrgicos (a propósito de 286 casos). Neurocirugía 2006; 17: 391-419.

Correspondencia postal: Dr. Secundino Martín-Ferrer. Servicio de Neurocirugía. Hospital Universitario Josep Trueta. 17007 Girona mento transverso asociada a la fractura de odontoides. En estos casos puede conseguirse una aceptable fusión ósea, pero persistir una incontinencia del ligamento transverso.

El autor favorece el uso de la Minerva moldeada como alternativa al uso del halo, aunque hoy día, la mayoría de los autores utilizan el halo en el tratamiento de estas fracturas ya que ofrece una mayor inmovilización; si bien la Minerva ofrece ventajas económicas.

\section{Bibliografía}

Anderson S, Rodrigues M, Olerud C: High complication rate associated with anterior screw fixation in elderly patients. Eur Spine J 9:56-60. 2000.

Lennarson PJ, Mostafari H, Traynelis VC, Walters BC: Management of Type II dens fractures: A case control study. Spine 25:1234-1237, 2000.

Traynelis VC: Evidence based management of Tipe II odontoid fractures. Clin Neurosurg 44:41-49, 1997.

P.A. Gómez López Madrid 